This is the submitted version of the following article:

Zhang X., Luo J., Lin H.-F., Tang P., Morante J.R., Arbiol J., Wan K., Mao B.-W., Liu L.-M., Fransaer J.. Tailor-made metal-nitrogen-carbon bifunctional electrocatalysts for rechargeable $\mathrm{Zn}$-air batteries via controllable MOF units. Energy Storage Materials, (2019). 17. : 46 - . 10.1016/j.ensm.2018.11.034,

which has been published in final form at https://dx.doi.org/10.1016/j.ensm.2018.11.034 @ https://dx.doi.org/10.1016/j.ensm.2018.11.034. This manuscript version is made available under the CC-BY-NC-ND 4.0 license http://creativecommons.org/licenses/by-nc-nd/4.0/ 


\title{
Tailor-made metal-nitrogen-carbon bifunctional electrocatalysts for rechargeable Zn-air batteries via controllable MOF units
}

\begin{abstract}
The majority of chemical syntheses involve the use of catalysts, which play a crucial role in the yield and conversion rates of chemical reactions. In view of the increasing demand for chemical commodities and specialties linked to the growth of the world's population and the living standards, highly efficient and low-cost catalysts are urgently required. The metal-nitrogen-carbon (M-N-C) catalysts family is one of the most promising candidates. In this work, a series of benzene-1,3,5-tricarboxylate linker based metal organic frameworks (MOFs) were used as self-sacrificial templates and tunable platform for designable preparation of M-N-C catalysts. Changing the pillars between the 2D layers and the nature of the metal ions in the pristine MOFs significantly influenced the structure, chemical composition and catalytic activity of the resulting M-N-C catalysts for the oxygen reduction reaction (ORR). Furthermore, the influence of the MOF units on the catalyst performance, the role of the metals in the M-N-C catalysts and the primary catalytically active sites for ORR were explored by a combination of density functional theory (DFT), in-depth structural and chemical/elemental characterizations, and electrochemical studies. Among the prepared catalysts, Co-BTC-bipy-700 exhibited the highest electrocatalytic activity for oxygen reduction reaction (ORR), which showed a larger limiting current density and similar half-wave potentials with less catalyst degradation and much higher methanol tolerance than the commercial $\mathrm{Pt} / \mathrm{C}$ catalyst. Meanwhile, as a bifunctional electrocatalyst, Co-BTC-bipy-700 catalyst was also employed for oxygen evolution reaction (OER) and demonstrated a lower overpotential (lowered by $140 \mathrm{mV}$ at a current density of $10 \mathrm{~mA} \mathrm{~cm}$ ) and better durability than $\mathrm{IrO}_{2}$. Furthermore, in terms of device performance, the $\mathrm{Zn}$-air battery enabled by Co-BTC-bipy-700 catalyst reached a maximum specific energy as high as $1009.8 \mathrm{Wh} \mathrm{kg}^{-1}$, which is $76.5 \%$ of the theoretical value $\left(1320 \mathrm{Wh} \mathrm{kg}^{-1}\right)$, and demonstrated higher discharge potential and lower charge potential than that based on the Pt/C catalyst. Importantly, the presented strategy for tailor-made M-N-C catalysts by controlling the synthesis of the pristine MOFs could offer a guide map for the future design of M-N-C catalysts family not only for electrochemical reactions but also beyond electrochemistry.
\end{abstract}

Keywords: metal-organic frameworks; anodic electrodeposition; Metal-Nitrogen-Carbon catalysis; oxygen reduction reaction; oxygen evolution reaction; rechargeable $\mathrm{Zn}$-air batteries.

\section{Introduction}

Without catalysts, our lifestyle would be significantly different. More than $80 \%$ of all chemicals and pharmaceuticals are made by catalysts. ${ }^{1}$ Although tremendous efforts have been made by the chemical industry, noble metal catalysts still dominate the market of energy-related catalysis and fine chemistry. ${ }^{2}$ It is urgent to find a suitable alternative due to the prohibitive cost and scarcity of these noble metals. Different types of transition metal based catalysts have been widely studied. ${ }^{3}$ Among various alternatives, a new class of metal (or metal compound)-nitrogen-carbon (M-N-C) catalysts have emerged as one of the most promising candidates, and they are 
used in a wide range of chemical reactions such as transesterification ${ }^{4}$, hydrogenation ${ }^{5-7}$, oxidative degradation ${ }^{8}$, Fischer-Tropsch synthesis ${ }^{9,} 10$ and especially for electrochemical reactions (e.g. hydrogen evolution reaction $(\mathrm{HER})^{11-15}$, oxygen evolution reaction $(\mathrm{OER})^{16-20}$, oxygen reduction reaction $(\mathrm{ORR})^{21-28}$ and carbon dioxide reduction ${ }^{29,30}$ ).

The traditional methods for preparing M-N-C catalysts can roughly be divided into two categories. The first one is the two-step method in which $\mathrm{N}$-doped carbon materials are subsequently loaded with metals. For example, Shaabani et al. synthesized three-dimensional nitrogen-doped graphene frameworks by hydrothermal and freeze-drying process, and then immobilized nickel nanoparticles on the prepared substrate. ${ }^{31}$ The second method is the one-step method in which a mixture of carbon, nitrogen and metal precursors is pyrolized. Metal/ $\mathrm{N}_{4}$ macrocycle complexes together with some carbon source are often used for fabricating M-N-C catalysts. ${ }^{26,32,33}$ Common inorganic salts (sulfates, acetates and chlorides) and organic compounds (including dicyandiamide, melamine and tripyridyl) have also successfully been employed as M-N-C catalyst precursor materials. ${ }^{34-36}$ Moreover, in order to improve the mass transport properties and increase the exposure of the active sites, templates were introduced into the synthesis process, such as $\mathrm{SBA}-15^{37,38}$ and $\mathrm{SiO}_{2}$ nanoparticles ${ }^{25,39}$.

In view of the above, metal-organic frameworks (MOFs), constructed from metal ions or clusters bridged by organic ligands, have been considered as ideal self-sacrificial templates for M-N-C catalysts due to their highly ordered cavities, open channels and rational composition and structure. ${ }^{2,40}$ These unique characteristics of MOFs allow them to serve as both template and precursor materials (metal, carbon and nitrogen). Furthermore, the highly ordered structure and chemical composition result in a homogeneous distribution of heteroatom and metal particles, which could provide more active sites after pyrolysis. Therefore, different kinds of MOFs have attracted attention as precursors for preparing M-N-C catalysts, such as cobalt-4'-(4-pyridyl)-4,2',6',4'-terpyridine ${ }^{41}$,

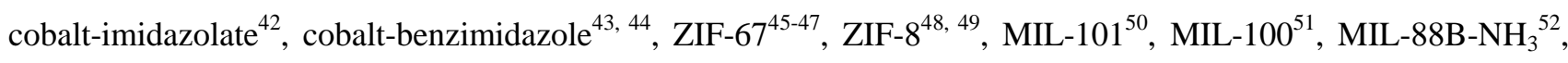
Co-BDC ${ }^{53}$ CPM-24 $4^{54}$ and enantiotopic chiral 3D MOFs (Co-BTC-MIDPPA $\mathbf{L}$ and $\left.\mathbf{R}\right)^{55}$. However, they are only the 
tip of the iceberg as more than 20,000 different MOFs have been created and the number is still increasing ${ }^{56,57}$. The large quantities of MOFs offer extensive possibilities for the M-N-C catalyst family but at the expense of endless lab work. The previous studies often suffer from the unclear influence of different metal nodes and linkers on the resulted catalysts. Similar studies for conventional method (mix metal salts with carbon resource, which could be easily adjusted) have been well discussed recently. However, it is hard to achieve this goal for MOF-derived materials due to the complexity of MOF structures. The separated studies and unclear influence of MOF units hampered scientific and industrial progress of MOF-derived catalysts. Therefore, for the sake of minimizing unnecessary lab work and to avoid both the consumption of time and resources, the critical problem is to gain rational and comprehensive insight into the influence of MOF units (i.e. organic ligands, metal units and interactions of these two parts) on key parameters of catalyst performance via experiments and computational chemistry. Unfortunately, the related research in this aspect is still very scarce. Due to the complexity of MOF structures, the role of metal and linkers in M-N-C structures based on MOFs is much more difficult to study than that of M-N-C structures prepared via common or conventional methods which mix precursors of metals, carbon, and nitrogen. In order to further improve the performance of MOF-derived materials, it is urgent to find a suitable platform enabled by rational methodologies.

In this work, rechargeable metal-air batteries, which are one of the most promising energy storage devices for practical domestic/industrial applications because of their high theoretical energy density, environmental benignity, safety and low cost, ${ }^{58-62}$ were chosen as the targeted application. For rechargeable metal-air batteries, OER and ORR are involved in the charge-discharge process. Therefore, designing an effective bifunctional catalyst is essential for rechargeable metal-air batteries. According to previous studies, ${ }^{16,19,40,63-66}$ the following concerns are important for ORR and OER of M-N-C catalysts: (1) large effective surface area for catalytic active sites; (2) high degree of graphitization and conductivity; (3) homogeneous distribution of heteroatoms and metal particles; (4) high Nitrogen content and suitable forms of N-C structure; (5) active metal species sites; (6) intimate connection 
between carbon and metal. Bearing these considerations in mind, a series of benzene-1,3,5-tricarboxylate (BTC) linker based MOFs, which work as a tunable platform due to the well-defined two-dimensional (2D) plane layers, have been successfully prepared by electrodeposition. The characteristics of the MOF units are changed via tailoring the pillars between the 2D layers and the central metal ions. After pyrolysis, significant differences in catalytic performance can be seen with different pristine MOFs. A combination of density functional theory (DFT) computation, in-depth structural and chemical/elemental characterizations, and electrochemical studies were used to explore (i) the influences of MOFs unit changes on the catalyst performance, (ii) the role of metal in M-N-C catalysts, and (iii) the primary catalytically active site of M-N-C structure for ORR. Among the prepared catalysts, Co-BTC-bipy-700 exhibited excellent electrocatalytic activity for both ORR and OER. For the rechargeable Zn-air battery test, this catalyst exhibited higher discharge potential and lower charge potential than $\mathrm{Pt} / \mathrm{C}$ catalyst. Moreover, the specific energy of Zn-air battery based on Co-BTC-bipy-700 catalyst reached $1041 \mathrm{Wh} \mathrm{kg}^{-1}$ at $3 \mathrm{~mA}$ $\mathrm{cm}^{-2}$, which is $80 \%$ of the theoretical value $\left(1320 \mathrm{Wh} \mathrm{kg}^{-1}\right)$. These results show that Co-BTC-bipy-700 catalysts are promising catalyst materials for rechargeable $\mathrm{Zn}$-air batteries.

\section{Results and discussion}

Tuned properties of M-N-C catalysts via MOFs units design (including thermal stability, carbon structure, $N$ content, distribution, structure and electrochemical double-layer capacitances)

A series of benzene-1,3,5-tricarboxylate (BTC) based MOFs, which act as a tunable platform due to the well-defined two-dimensional (2D) layers, have been successfully prepared by anodic electrodeposition (Figure 1). $\mathrm{Ni}(\mathrm{HBTC})(\mathrm{DMF})_{2}$ (abbreviated as Ni-BTC-DMF herein) was constructed by offset stacking of 2D layers with honeycomb pores. In each layer, Ni (II) is bonded to three BTC linkers, with one bidentate carboxylic group and two monodentate carboxylic groups. The free carbonyls in the monodentate carboxylic groups are further bonded to a proton through hydrogen boding, forming an overall neutral framework. The axial position of $\mathrm{Ni}$ (II) was occupied by DMF molecules. The sheets are pillared by 4,4'-bipyridine along the $c$ axis to form 3D porous 
framework structure $\left(\mathrm{Ni}(\mathrm{HBTC})\left(4,4^{\prime}\right.\right.$-bipy)). $\mathrm{Ni}(\mathrm{HBTC})\left(4,4^{\prime}\right.$-bipy) possesses two types of channels: honeycomb channels along the [001] direction and rectangular channels along the [110] direction. The Ni(HBTC)(4,4'-bipy) (abbreviated as Ni-BTC-bipy herein) was further tailored by replacement of $\mathrm{Ni}$ (II) with Co (II) to obtain Co(HBTC)(4,4'-bipy) (abbreviated as Co-BTC-bipy herein). As evidenced by the SEM images (Figure 1), all the MOFs exhibited similar hexagonal morphology. The XRD patterns of different MOFs (Figure S1-S3) are in agreement with the theoretical XRD patterns. These results demonstrate the successful electrodeposition of the desired MOFs. In addition, the XRD patterns of Ni-BTC-bipy and Co-BTC-bipy are very similar, indicating that the crystal structures of these two kinds of MOFs are almost the same. As the coordinating ability of Ni (II) and Co (II) are different, Co-BTC-bipy was prepared at a lower temperature $\left(30^{\circ} \mathrm{C}\right)$. This phenomenon is consistent with the previous report by Li et al. using solvothermal methods. ${ }^{67}$ Compared with solvothermal methods, the visible and adjustable electrodeposition process is easier to control the reaction process and avoids the influence of anions from salts. ${ }^{68,69}$ SEM images of the as-prepared electrodes by anodic electrodeposition of Co-BTC-bipy at $60{ }^{\circ} \mathrm{C}$ and $120{ }^{\circ} \mathrm{C}$ are presented in Figure S4. Additionally, the feasibility of large scale production is important for practical industrial applications. Herein, when two electrodes connected in series, there is no difference for electrodeposition of Co-BTC-bipy (Figure S5), which shows that this method could be used for preparing multi-electrodes simultaneously. The same cobalt plate was used 10 times as the substrate for anodic electrodeposition of Co-BTC-bipy. After each time, the cobalt plate was dipped into dilute $\mathrm{HCl}$ solution and polished with sand paper. After 10 times, the Co-BTC-bipy covered cobalt plate looks the same as that after the first time (the inset of Figure S5). This proves that our procedure has the potential for large scale production.

In order to get M-N-C catalysts, the as-prepared MOFs were pyrolyzed under $\mathrm{N}_{2}$ atmosphere at different temperatures. Based on the thermogravimetric analysis (TGA) results (Figure S6), it is concluded that the onset temperature of carbonization of the framework for Ni-BTC-DMF, Ni-BTC-bipy and Co-BTC-bipy are $395{ }^{\circ} \mathrm{C}$, $379{ }^{\circ} \mathrm{C}$ and $312{ }^{\circ} \mathrm{C}$, respectively. Because of the decreased coordination ability of Co (II), the decomposition 
temperature of Co-BTC-bipy is lower than Ni-BTC-bipy. Before decomposition of the framework, there is one weight loss event each for Ni-BTC-bipy and Co-BTC-bipy, which corresponds to the release of adsorbed molecules (around 15\% and 10\% weight loss, respectively). In addition, when the linker is changed, there is no obvious decomposition temperature changes are observed between Ni-BTC-DMF and Ni-BTC-bipy. However, multi-steps weight loss events can be observed for Ni-BTC-DMF, with around $45 \%$ weight loss, which is probably caused by the loss of DMF molecules in the structure of Ni-BTC-DMF. ${ }^{70}$ Based on the composition of Ni-BTC-DMF, DMF was considered as $\mathrm{N}$ source for M-N-C catalysts. Therefore, the loss of DMF molecules from the structure of Ni-BTC-DMF could lead to the low N content for Ni-BTC-DMF derived from Ni-BTC-DMF.

The composition and structure of M-N-C catalysts derived from MOFs were investigated by Raman spectroscopy, CHN analysis, XPS and TEM. Raman spectroscopy was used to analyze the degree of structural order with respect to a perfect graphitic carbon structure. Generally speaking, the D-band at $\sim 1350 \mathrm{~cm}^{-1}$ and a G-band at $\sim 1585 \mathrm{~cm}^{-1}$ are reflection of ideal and disordered graphitic lattices, respectively. The intensity ratio of $D$ and $G$ bands $\left(I_{D} / I_{G}\right)$ can be regarded as a measure of the carbon crystalline order of carbon materials. ${ }^{71}$ A reduction of $I_{D} / I_{G}$ ratio of carbon materials means an increase of graphitic content, which would benefit the charge transfer for electrochemical catalysts. ${ }^{72}$ Based on Raman spectra (Figure S6-S9), the $I_{\mathrm{D}} / I_{\mathrm{G}}$ ratios of different catalysts are obtained (Figure 2a). The $\mathrm{I}_{\mathrm{D}} / \mathrm{I}_{\mathrm{G}}$ values are $1.13,0.88,1.47,0.92,0.84$, and 0.72 for Ni-BTC-DMF-700, Ni-BTC-DMF-900, Ni-BTC-bipy-700, Ni-BTC-bipy-900, Co-BTC-bipy-700 and Co-BTC-bipy-900 catalysts, respectively. With increase of the pyrolysis temperature, the $I_{\mathrm{D}} / I_{\mathrm{G}}$ ratio decreases a lot for all the MOFs derived catalysts. Compared with Ni-BTC-DMF based catalysts, Ni-BTC-bipy show higher $I_{\mathrm{D}} / I_{\mathrm{G}}$ ratio, which indicates that the 4,4'-bipyridine linker can result in more heteroatoms in the carbon structure after pyrolysis. This result is in agreement with TGA test. Among these pristine MOFs, Co-BTC-bipy based catalyst shows the lowest $I_{\mathrm{D}} / I_{\mathrm{G}}$ ratio. The difference of $I_{\mathrm{D}} / I_{\mathrm{G}}$ ratio between Co-BTC-bipy and Ni-BTC-bipy based catalysts could be caused by the different catalytic ability of different metals for carbon graphitization. The detailed mechanism of metal 
nanoparticles in catalytic graphitization is still not clear, which are probably related to carbon solubility and carbon diffusion coefficients in the different metal. ${ }^{73}$ It is worth mentioning that Co-BTC-bipy-700 $\left(I_{\mathrm{D}} / I_{\mathrm{G}}=0.84\right)$ and Co-BTC-bipy-900 $\left(I_{\mathrm{D}} / I_{\mathrm{G}}=0.72\right)$ show even lower $I_{\mathrm{D}} / I_{\mathrm{G}}$ ratio than multi-walled carbon nanotubes $(\mathrm{MCNTs})$, whose $I_{\mathrm{D}} / I_{\mathrm{G}}$ ratio is $0.92($ Figure $\mathbf{S 1 0})$.

The bulk N content (at.\%) of catalysts were explored by CHN analysis (Figure 2b). With increase of the pyrolysis temperature, the $\mathrm{N}$ content decreases for all the samples. Comparing with Ni-BTC-DMF and Ni-BTC-bipy, Ni-BTC-bipy derived catalysts $\left(5.9\right.$ at. $\%$ for $700{ }^{\circ} \mathrm{C}$ and 2.8 at. $\%$ for $900{ }^{\circ} \mathrm{C}$ ) show much higher $\mathrm{N}$ content than Ni-BTC-DMF (1.9 at. $\%$ for $700{ }^{\circ} \mathrm{C}$ and 1.3 at. $\%$ for $900{ }^{\circ} \mathrm{C}$ ), which is related to the loss of DMF molecules in the structure of Ni-BTC-DMF during pyrolysis, which can be proved by TGA results (Figure S6). These results reveal that the MOF ligand has a big influence on the $\mathrm{N}$ content of the as-prepared catalysts. When two MOFs which have similar $\mathrm{N}$ content in the structural unit are pyrolized, the resulting M-N-C catalyst show higher $\mathrm{N}$ content when the metal atoms are directly coordinated to the $\mathrm{N}$ atoms. In addition, the type of metal ion has some effect on the $\mathrm{N}$ content as well, which is probably caused by the difference in thermal stability and the ability to catalyze carbon growth between Ni-BTC-bipy and Co-BTC-bipy. A similar influence of metal particles on nitrogen content of N-C materials was observed by Kudashov et al. as well. ${ }^{74}$ The $\mathrm{N}$ contents of Co-BTC-bipy based catalysts are 5.0 at. $\%$ and 2.2 at. $\%$ at the pyrolysis temperature of $700{ }^{\circ} \mathrm{C}$ and $900{ }^{\circ} \mathrm{C}$, respectively. Furthermore, the metal content was calculated from the $\mathrm{CHN}$ analysis and metal oxide residues (based on phase diagrams of $\mathrm{Ni}-\mathrm{O}_{2}$ and $\mathrm{Co}-\mathrm{O}_{2}$ binary systems shown in Figure S11), and the results are displayed in Table S2.

The electrochemical double-layer capacitance, which is related to the electrochemical surface area of different catalysts (mass loading: $\sim 0.25 \mathrm{mg} \mathrm{cm}^{-2}$ ) were measured by cyclic voltammetry (CV) on a rotating disk electrode (RDE) in a non-Faradaic region (Figure S12-S17). As these catalysts are composite materials, it is difficult to accurately quantify their electrochemical surface areas. However, for qualitative analysis, the electrochemical double-layer capacitances are still very useful for comparing similar materials with the same mass loading. At a 
mass loading of $0.25 \mathrm{mg} \mathrm{cm}^{-2}$ on the RDE, the electrochemical double-layer capacitance of Ni-BTC-DMF-700, Ni-BTC-DMF-900, Ni-BTC-bipy-700, Ni-BTC-bipy-900, Co-BTC-bipy-700 and Co-BTC-bipy-900 are 2.06, 1.44, $0.81,0.57,2.87$, and $1.43 \mathrm{mF} \mathrm{cm}^{-2}$, respectively. Comparing the influence of different pillar linkers, the Ni-BTC-DMF derived materials exhibit higher capacitance than Ni-BTC-bipy based materials. It is speculated that the intermolecular short contact interactions between coordinated pillar (organic solvent) and coordinated carboxylate group in Ni-BTC-DMF is weaker than that in Ni-BTC-bipy, leading to obviously release of DMF pillars. Therefore, more pores and space will be produced during pyrolysis. Concerning different metals, the detailed function of metal particles during pyrolysis is still unclear. It is well known that different metals have different catalytic ability for carbon growth, which could eventually lead to different carbon net structures.

Furthermore, the near-surface elemental compositions (atomic percentage) based on full scan survey XPS spectra for different catalysts are shown in Table S3. There is a huge difference between the full scan survey XPS spectra and CHN analysis for metal contents, because the metal nanoparticles are covered by a carbon layer while for XPS tests, the information depth is less than $10 \mathrm{~nm} \cdot{ }^{19,75,76}$ Furthermore, the high-resolution XPS spectra of the Ni $2 \mathrm{p}$ (Figure S18a) and Co 2p (Figure S18b) were used for determining chemical states of transition metals. Because of low metal content on the surface of Ni-BTC-DMF-900 and Co-BTC-bipy-700, it is hard to get sharp peaks of Ni 2p or Co 2p. For the other Ni based catalysts, the XPS spectra of the Ni 2p (Figure S18a) all exhibit two main peaks at $853.3 \pm 0.3 \mathrm{eV}$ and $870.5 \pm 0.3 \mathrm{eV}$ without any obvious satellites, corresponding to the metallic dominant structure. Two weak peaks are assigned to $\mathrm{NiN}_{\mathrm{x}}(855.3 \pm 0.3 \mathrm{eV})$ and $\mathrm{NiO}(856.8 \pm 0.3 \mathrm{eV}$, oxidized in the air), respectively. ${ }^{77-80}$ The similar results for Co based catalysts with different locations of peaks (for $\mathrm{Co}^{0}, \mathrm{CoN}_{\mathrm{x}}$ and $\mathrm{CoO})^{16,81-83}$ are shown in (Figure S18b), which indicates $\mathrm{Co}^{0}$ as the dominant chemical states of Co. These results are in good agreement with HRTEM observations. Elemental compositions (atomic percentage) based on XPS spectra (full scan survey) show lower $\mathrm{N}$ content but the similar trend that the total $\mathrm{N}$ content decreases with increasing temperature for all catalysts. To further comprehend the chemical states of $\mathrm{N}$-heteroatoms, the 
high-resolution XPS spectra of the N 1s (Figure 3) are used to investigate N-heteroatom species. All the samples show obvious peaks of $\mathrm{N} 1 \mathrm{~s}$. The binding energies of about $398.5 \pm 0.2 \mathrm{eV}, 400.5 \pm 0.3 \mathrm{eV}$ and $401.3 \pm 0.3 \mathrm{eV}$ were assigned to pyridinic $\mathrm{N}$, pyrrolic $\mathrm{N}$ and graphitic $\mathrm{N}$, respectively. In addition, transition metals could be coordinated with different number of pyrrolic or pyridinic $\mathrm{N}$ atoms in the conjugate carbon plane, namely $\mathrm{M}-\mathrm{N}_{\mathrm{x}}$ site. Therefore, the peak intensity for pyridinic $\mathrm{N}$ and pyrrolic $\mathrm{N}$ should also include a contribution from $\mathrm{M}-\mathrm{N}$ bonds. ${ }^{25,40,84}$ Upon deconvolution of the $\mathrm{N} \mathrm{1s}$, the relative contents (based on $\mathrm{N}$ content) of different $\mathrm{N}$-heteroatom species are presented in Figure 3. The graphitic $\mathrm{N}$ is most stable at high temperature. The relative content (based on $\mathrm{N}$ content) of pyridinic $\mathrm{N}$ was dramatically decreased with increasing temperature. Interestingly, the relative content of pyrrolic $\mathrm{N}$ is almost the same for all samples, even though pyrrolic $\mathrm{N}$ is not stable at high temperatures (above $\left.700{ }^{\circ} \mathrm{C}\right) .{ }^{85,86}$ This could be caused by the change of the formation energy of pyrrolic $\mathrm{N}$ in the M-N-C structure, which in good agreement with the EELS mapping and DFT results. It is discussed in detail in the EELS mapping analysis. Combining high-resolution XPS spectra with CHN analysis, the contents of different N-heteroatom species are shown in Table S4. The different linkers have significant influence on N content, which is confirmed by CHN analysis. Among these catalysts, Ni-BTC-bipy-700 shows the highest $\mathrm{N}$ content $(5.9$ at. $\%$ based on total amount of $\mathrm{C}, \mathrm{H}$ and $\mathrm{N}$ ), including 2.2 at.\% pyridinic $\mathrm{N}, 1.4$ at.\% pyrrolic $\mathrm{N}$ and 2.3 at.\% graphitic $\mathrm{N}$. The different N-heteroatom species can have a significant influence on the catalytic activity. The details of different $\mathrm{N}$-heteroatom species in potential microstructures for each elementary steps of ORR are discussed in the section of

\section{"DFT calculation of active sites in M-N-C structure".}

The general view and magnified details of the ADF-STEM images are displayed in Figure 4 and Figure S19-S22. For all the samples, the metal-containing nanoparticles are covered by a carbon layer or embedded in the carbon layer. The diameters of these particles are in the range of 10 to $100 \mathrm{~nm}$. Moreover, the relative compositions of $\mathrm{Co}, \mathrm{N}, \mathrm{O}$ and $\mathrm{C}$ elements of these samples have been mapped by means of EELS analysis using the Hartree-Slater model for signal quantification and power law for background removal. ${ }^{87}$ In order to extract the 
maps and compute the relative composition, we have analyzed the corresponding K-edge for C (284 eV), N (401 $\mathrm{eV})$ and $\mathrm{O}(532 \mathrm{eV})$ and the $\mathrm{L}_{2,3}$-edge in the case of $\mathrm{Co}(779 \mathrm{eV})$. The relative composition maps of $\mathrm{C}$ and $\mathrm{N}$ were explored by EELS analysis as well, except for Ni-BTC-DMF based catalysts due to their low $\mathrm{N}$ content. The $\mathrm{N}$ content based on total amount of $\mathrm{C}$ and $\mathrm{N}$ by EELS analysis are $7.70 \pm 2.13$ at. $\%, 3.08 \pm 0.82$ at. $\%, 6.1 \pm 2.9$ at. $\%$ and $3.7 \pm 2.3$ at.\% for Ni-BTC-bipy-700, Ni-BTC-bipy-900, Co-BTC-bipy-700 and Co-BTC-bipy-900 catalysts, respectively. With increasing temperature, the $\mathrm{N}$ content decreases. These results are in good agreement with XPS and CHN analyses. EELS chemical composition maps clearly show a $\mathrm{N}$ content in the carbon layer, which originates from the $\mathrm{C}-\mathrm{N}$ structure. In addition, it is worth mentioning that metal particles covered by the carbon layer are often adjacent or close to nitrogen atoms (the relative composition of $\mathrm{N}$ in the metal nanoparticles region is much higher than that on the region without metal particles), suggesting possible M-N bonding, ${ }^{88}$ which is in agreement with the XPS analysis. Therefore, the high $\mathrm{N}$ atomic content around the metal nanoparticles should originate from the M-N-C structure. Furthermore, there are some rich $\mathrm{C}-\mathrm{N}$ cavities produced by the metal nanoparticles etched from the C-N shell support (Figure 4). The presence of rich C-N cavities together with the high relative composition of $\mathrm{N}$ near the metal particles indicates that the metal nanoparticles could stabilize $\mathrm{N}$ in the graphite framework. This phenomenon might be caused by the change of formation energy of C-N structure after formation of the M-N-C structure. Even the influences of metal source on the $\mathrm{N}$ content in conventional method have been reported by previous researchers, a reasonable theoretical explanation is still unseen. Formation energies (in $\mathrm{eV}$ ) of potential configurations of $\mathrm{M}-\mathrm{N}-\mathrm{C}$ microstructures presented in this work based on DFT were shown in Table S5, the formation energies of $\mathrm{N}_{\text {graphite }}-\mathrm{G}(0.62 \mathrm{eV})$ structure are smaller than both of Ni- $\mathrm{N}_{\text {graphite }}-\mathrm{C}(4.20 \mathrm{eV})$ and Co- $\mathrm{N}_{\text {graphite }}-\mathrm{C}(5.34 \mathrm{eV}) .{ }^{89}$ However, the formation energies of $\mathrm{N}_{\text {pyrid }}-\mathrm{G}(3.32 \mathrm{eV})$ and $\mathrm{N}_{\text {pyrro }}-\mathrm{G}(10.21 \mathrm{eV})$ are dramatically reduced after forming the $\mathrm{M}-\mathrm{N}-\mathrm{C}$ structure. The formation energies of $\mathrm{Co}-\mathrm{N}_{\text {pyrid3 } 3}-\mathrm{C}, \mathrm{Co}-\mathrm{N}_{\text {pyrid }}-\mathrm{C}$, Co- $\mathrm{N}_{\text {pyrro2 }}-\mathrm{C}$ and Co- $\mathrm{N}_{\text {pyrro3 }}-\mathrm{C}$ are $2.61 \mathrm{eV}, 1.31 \mathrm{eV}, 7.70 \mathrm{eV}$ and $6.59 \mathrm{eV}$, respectively. Therefore, the $\mathrm{N}$ would be enriched around metal particles and more for pyridinic $\mathrm{N}$ and pyrrolic $\mathrm{N}$, which is in good agreement with XPS 
results as well. In addition, all the Ni-based M-N-C structures show smaller formation energies than corresponding Co-based materials. This might be the reason why Ni-based materials show higher $\mathrm{N}$ content than Co-based materials even with the same structure of the pristine MOFs and using the same pyrolysis condition. Meanwhile, based on the STEM-EELS mapping, the $\mathrm{O}$ signal seems to be always accompanied by $\mathrm{C}$ and $\mathrm{N}$ signals rather than metal signal, meaning that the metal nanoparticles are mainly present in their metallic form and $\mathrm{M}-\mathrm{N}_{\mathrm{x}}$ compounds. The HRTEM micrographs of Co-BTC-bipy-700 and Co-BTC-bipy-900 (Figure 5) show the morphology of the nanoparticles, which are surrounded by a graphitic C-N shell. The HRTEM image and its corresponding colored power spectrum (FFT) obtained on the red square region indicate that the nanoparticle crystallized in the hexagonal Co crystal phase, [P63/MMC]-space group 194, with lattice parameters of $a=b=0.24968 \mathrm{~nm}, c=0.40308 \mathrm{~nm}$ and $\alpha=\beta=90^{\circ}, \gamma=120^{\circ}$, as visualized from the $[000 \overline{1}]$ direction. Upon increasing pyrolysis temperature, the crystal phase of the Co nanoparticles does not change.

\section{DFT calculation of active sites in M-N-C structure}

Although Co-N-C or Ni-N-C for ORR has been explored by DFT in previous studies, only few potential configurations of M-N-C microstructures have been considered. ${ }^{90,91}$ However, different potential configurations of M-N-C microstructures may exist within the same material for heteroatom doped carbon based catalysts. ${ }^{92}$ There are eight different basic configurations of M-N-C microstructures in the M-N-C structure (Figure 6a). Different $\mathrm{N}$-heteroatom species and structures influence the catalytic activity of overall ORR steps differently. Therefore, it is important to know which kind of configurations of M-N-C microstructures are primary catalytically active sites for ORR.

In this work, the performances of different potential microstructures as an ORR catalyst were evaluated theoretically by computing their free energy diagram for ORR with each elementary steps (four-electron way) at a fixed overpotential $(\eta=0.4 \mathrm{~V})$, which is based on real conditions. The different N-heteroatom species and structures have a significant influence on the catalytic activity of overall ORR steps (Figure 6a). Firstly, all reaction 
steps on the $\mathrm{Ni}-\mathrm{N}_{\text {graphite }}-\mathrm{C}$ surfaces are downhill except for the $\mathrm{OH}^{*}$ formation, which is $1.44 \mathrm{eV}$ uphill. This step is the rate-determining step (RDS) of the overall ORR for the $\mathrm{Ni}-\mathrm{N}_{\text {graphite }}-\mathrm{C}$ catalyst. When $\mathrm{Co}$ replaces $\mathrm{Ni}$, the $\mathrm{OH} *$ formation is thermodynamically favorable. However, the last step, $\mathrm{OH}^{*}$ desorption, is $1.89 \mathrm{eV}$ uphill. Hence, a four-electron oxygen reduction mechanism should be thermodynamically unfavorable on both $\mathrm{Ni}-\mathrm{N}_{\text {graphite }}-\mathrm{C}$ and Co- $\mathrm{N}_{\text {graphite }}-\mathrm{C}$ surfaces. There are four kinds of potential configurations of $\mathrm{M}-\mathrm{N}_{\text {pyrid }}-\mathrm{C}$ microstructures (Figure $6 \mathbf{b}$ ). The step from $\mathrm{O}_{2} *$ to $\mathrm{HOO}^{*}$ is the RDS during the overall ORR on the $\mathrm{Ni}-\mathrm{N}_{\text {pyrid }}-\mathrm{C}$ surface. The corresponding free energy differences for RDS of $\mathrm{Ni}-\mathrm{N}_{\text {pyrid }}-\mathrm{C}$ structures are $0.31 \mathrm{eV}, 0.45 \mathrm{eV}, 0.51 \mathrm{eV}$ and $0.74 \mathrm{eV}$ for $\mathrm{Ni}-\mathrm{N}_{\text {pyrid1 }}-\mathrm{C}$, $\mathrm{Ni}-\mathrm{N}_{\text {pyrid2 }}-\mathrm{C}, \mathrm{Ni}-\mathrm{N}_{\text {pyrid3 } 3}-\mathrm{C}$ and $\mathrm{Ni}-\mathrm{N}_{\text {pyrid4 }}-\mathrm{C}$, respectively. These $\mathrm{Ni}-\mathrm{N}_{\text {pyrid }}-\mathrm{C}$ structures show more favorable for ORR than $\mathrm{Ni}-\mathrm{N}_{\text {graphite }}-\mathrm{C}$ structures with free energy difference of the rate-determining-step as high as $1.44 \mathrm{eV}$ for the $\mathrm{OH}^{*}$ formation. But all $\mathrm{RDS}$ of $\mathrm{Ni}-\mathrm{N}_{\text {pyrid }}-\mathrm{C}$ structures are still uphill. Interestingly, for the $\mathrm{Co}-\mathrm{N}_{\text {pyridz }}-\mathrm{C}$ and Co- $\mathrm{N}_{\text {pyrid4 }}-\mathrm{C}$ structure, all the steps are downhill, indicating a four-electron ORR pathway could be thermodynamically favorable on these structures. However, with the number of connected $\mathrm{N}$ atoms decreases, Co- $\mathrm{N}_{\text {pyrid2 } 2}-\mathrm{C}$ and $\mathrm{Co}-\mathrm{N}_{\text {pyrid } 1}-\mathrm{C}$ seem to be unfavorable for the $\mathrm{OH}^{*}$ desorption. The last possible N-heteroatom

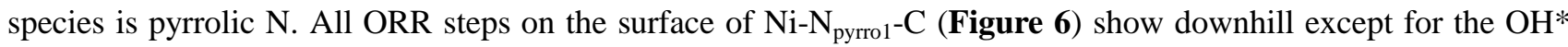
desorption which is slightly uphill $(0.03 \mathrm{eV})$. When the $\mathrm{N}$ content increases in the microstructures, the formation of $\mathrm{HOO}^{*}$ becomes unfavorable. Because $\mathrm{Ni}-\mathrm{N}_{\text {pyrrol }}-\mathrm{C}$ shows the lowest free energy difference of $\mathrm{RDS}(0.03 \mathrm{eV})$ among all potential configurations of $\mathrm{Ni}-\mathrm{N}-\mathrm{C}$ microstructures $\left(0.31 \mathrm{eV}\right.$ for $\mathrm{Ni}-\mathrm{N}_{\text {pyrid } 1}-\mathrm{C}$ and $1.44 \mathrm{eV}$ for Ni-N $\mathrm{N}_{\text {graphite }}-\mathrm{C}$ ), Ni-N $\mathrm{N}_{\text {pyrrol }}-\mathrm{C}$ might be the most promising active site for the four-electron ORR.

For the different Co- $\mathrm{N}_{\text {pyrro }}-\mathrm{C}$ microstructures, a four-electron ORR can only happen favorably on the surface of Co- $\mathrm{N}_{\text {pyrro2 }}-\mathrm{C}$ with all ORR steps going downhill. Therefore, the active sites of Co- $\mathrm{N}_{\text {pyrid3 } 3}-\mathrm{C}, \mathrm{Co}-\mathrm{N}_{\text {pyrid4 }}-\mathrm{C}$ and Co- $\mathrm{N}_{\text {pyrro2 }}-\mathrm{C}$ could be the primary catalytically active site for ORR in Co-N-C catalysts. It is worth stressing that $\mathrm{Co}-\mathrm{N}_{\text {pyrid4 }}-\mathrm{C}$ is not the only active site in $\mathrm{Co}-\mathrm{N}-\mathrm{C}$ catalyst. In fact, $\mathrm{Co}-\mathrm{N}_{\text {pyrid3 } 3}-\mathrm{C}$ and $\mathrm{Co}-\mathrm{N}_{\text {pyrro2 }}-\mathrm{C}$ can play an important role as well, which is proven by DFT calculations for the first time. This useful information would 
clearly guide the further improvement of Co-N-C catalysts. Based on the DFT calculation results, it is concluded as follows: (i) the primary catalytically active sites for ORR in Co-N-C catalysts include Co- $\mathrm{N}_{\text {pyrid }}-\mathrm{C}, \mathrm{Co}-\mathrm{N}_{\text {pyrid3 } 3}-\mathrm{C}$ and Co- $\mathrm{N}_{\text {pyrro2 }}-\mathrm{C}$; (ii) the $\mathrm{N}$ content of pyridinic $\mathrm{N}$ and pyrrolic $\mathrm{N}$ could play an important role in the ORR for both Co-N-C catalyst and Ni-N-C catalyst; (iii) Co-N-C catalysts could show better ORR catalytic performance than Ni-N-C catalysts. However, in the real conditions, the situation will be much more complicated. A lot of other factors would have influenced the ORR performance of the M-N-C catalysts. For example, there is no perfect graphene framework for loading M-N-C structure. In the following parts, we will discuss the present M-N-C catalysts for the ORR under practical conditions by electrochemical methods.

\section{Enhancement of catalytic performance based on MOFs units design}

The catalytic performance of as-prepared catalysts was explored by LSV (Figure 7). Compared to the blank electrode, all catalysts show obvious catalytic performance for ORR. Firstly, the effect of the pyrolysis temperature is studied (Figure 7a-7c). For the Ni-BTC-DMF based catalyst, Ni-BTC-DMF-900 displays better catalytic performance than Ni-BTC-DMF-700, even though Ni-BTC-DMF-700 shows higher N content and electrochemical double-layer capacitance (indicating larger electrochemical surface area). ${ }^{93}$ However, the $\mathrm{N}$ content of both Ni-BTC-DMF-700 and Ni-BTC-DMF-900 are very low (especially pyridinic $\mathrm{N}$ and pyrrolic $\mathrm{N}$, whose total content is less than 0.5 at.\%). Among all $\mathrm{M}-\mathrm{N}-\mathrm{C}$ structures, the $\mathrm{Ni}-\mathrm{N}_{\text {pyrro }}-\mathrm{C}$ and $\mathrm{Ni}-\mathrm{N}_{\text {pyrid }}-\mathrm{C}$ structures are related to active sites for the ORR based on the DFT results, the structure of carbon might dominate the catalytic performance of Ni-BTC-DMF based catalysts. Because of this, we call this C-dominant behavior. After changing the pillars to 4,4'-bipyridine, the N content of MOFs-derived catalysts (i.e. M-BTC-bipy-700 and M-BTC-bipy-900 ) increased a lot. For Co-BTC-bipy based materials, both of these two catalysts show very low $I_{\mathrm{D}} / I_{\mathrm{G}}$ ratios, meaning high graphitization of these materials. Therefore, the real structure might be close to the DFT configurations. Co-BTC-bipy-700 shows better performance than Co-BTC-bipy-900 because Co-BTC-bipy-700 has a higher N content (especially, pyridinic $\mathrm{N}$ and pyrrolic $\mathrm{N}$ are almost 5 times higher) and larger electrochemical surface area 
(i.e. higher electrochemical double-layer capacitance). These results are in good agreement with DFT and XPS results. As in this situation, the number of effective active sites might dominate the catalytic performance, which can be denoted as "N-dominated behavior". The Ni-BTC-bipy-700 shows slightly higher limiting current density than Ni-BTC-bipy-900 (Figure 7b). This is caused by the change of $\mathrm{N}$ content, which is similar to the Co-BTC-bipy based materials. On the other hand, this N-dominated behavior effect is not as strong as for Co-BTC-bipy based materials. This is possible because of the high $I_{\mathrm{D}} / I_{\mathrm{G}}$ ratio of Ni-BTC-bipy. When the pyrolysis temperature increases, the $I_{\mathrm{D}} / I_{\mathrm{G}}$ ratio decreases significantly, which would benefit the ORR. A similar phenomenon is also observed in Ni-BTC-DMF based materials. Therefore, for Ni-BTC-bipy based materials, the structure of the carbon, the electrochemical surface area and the $\mathrm{N}$ content show a synergistic effect for the ORR, which can be classified as "synergistic effect behavior".

Compared to Ni-BTC-DMF based catalysts, Ni-BTC-bipy based catalysts show better performance at both pyrolysis temperatures, although Ni-BTC-DMF based catalysts show smaller $I_{\mathrm{D}} / I_{\mathrm{G}}$ ratio and higher electrochemical double-layer capacitance than Ni-BTC-bipy. This is caused by the large difference in the $\mathrm{N}$ content. With increasing pyrolysis temperature, the differences in catalytic ability between Ni-BTC-bipy-900 and Ni-BTC-DMF-900 are smaller than at low pyrolysis temperature. This is probably due to the decrease of the $\mathrm{N}$ content for Ni-BTC-bipy based catalyst at high pyrolysis temperatures and the lower $I_{\mathrm{D}} / I_{\mathrm{G}}$ ratio of Ni-BTC-DMF based catalyst. Therefore, when the metal atoms are directly connected to $\mathrm{N}$ atoms in the pristine MOF, the resulting M-N-C material has more favorable catalytic behavior for the ORR. Co-BTC-bipy-700 exhibits better catalytic activity for ORR than Ni-BTC-bipy-700 (Figure 7e). This could be attributed to two reasons: (1) The metal ions of MOFs will lead to different active sites $\left(\mathrm{Co}-\mathrm{N}_{\mathrm{x}}-\mathrm{C}\right.$ show better catalysts performance than $\left.\mathrm{Ni}-\mathrm{N}_{\mathrm{x}}-\mathrm{C}\right)$, which is proven by DFT results as well; (2) Different metals have different ability to catalyze carbon growth, which will have an influence on the structure of the carbon after pyrolysis and on the electrochemical surface area.

The commercial Pt/C (10 \%) catalyst was used as reference sample at same mass loading as Co-BTC-bipy-700. 
At this mass loading of commercial Pt/C (10\%), the mass loading of Pt is around $50 \mu \mathrm{g} \mathrm{cm}^{-2}$ (higher than "standard" loading of $20 \mu \mathrm{g} \mathrm{cm}^{-2}$ ). Interestingly, the onset potential of Co-BTC-bipy-700 is lower than Pt/C catalyst (Figure 8a), but with a larger limiting current density and similar half-wave potentials. While long-term stability is an important parameter for high-performance catalysts, Co-BTC-bipy-700 catalyst again outperforms the Pt/C catalyst. After 2000 CV cycles (in the range of $0.5 \mathrm{~V}-1 \mathrm{~V} v s$. RHE), the LSV curve of Co-BTC-bipy-700 catalyst shows only minor changes whereas the limiting current density of the Pt/C catalyst decreased a lot.

Furthermore, another advantage of Co-BTC-bipy-700 catalyst is the excellent tolerance to methanol (Figure 8b). With the addition of $1 \mathrm{M}$ methanol, $\mathrm{Pt} / \mathrm{C}$ catalyst shows an obvious peak of methanol oxidation and the cathodic peak corresponding to the ORR disappears. On the contrary, there is no change for the Co-BTC-bipy-700 catalyst, revealing its potential applications in direct methanol fuel cells. Moreover, considering economic and environmental impact, the recycling of catalysts is a big issue. Magnetic separation was recognized as a gentle and economical way to solve this issue. ${ }^{94-96}$ The recycling of Co-BTC-bipy-700 catalyst by magnetic separation in $1 \mathrm{M}$ $\mathrm{KOH}$ solution proves that magnetic separation is an effective way to recycle Co-BTC-bipy-700 catalyst (Figure S23 a-b). Even after one month, the Co-BTC-bipy-700 catalyst can be easily recycled by magnetic separation (Figure S23 c-d), which can be attributed to the protection of the cobalt by the carbon layer.

To know the electron transfer process of the ORR involving the as-prepared samples, LSV on RDE were recorded at rotation speeds from $400 \mathrm{rpm}$ to $2000 \mathrm{rpm}$ as shown in Figure S24a-S31a. Based on Koutecky-Levich $(\mathrm{K}-\mathrm{L})$ plots (Figure S24b-S31b), the electron transfer numbers $(n)$ per oxygen molecule is calculated in the potential range $0.45 \mathrm{~V}-0.6 \mathrm{~V}$. Commercial MCNTs and Pt/C were explored using the same method as control groups,. The calculated values of $n$ at various potentials are presented in Figure 9a. Among these catalysts, MCNTs show the smallest $n$ values ( 1.7) for ORR. The electron transfer numbers of Pt/C and Co-BTC-bipy-700 catalysts for ORR are 3.9 and 4.0, respectively, which is typical for the 4-electron ORR. The kinetic differences of catalytic ORR between different samples are investigated by Tafel plots (Figure 9b). Generally speaking, lower Tafel slopes 
imply faster kinetics. ${ }^{97}$ The Tafel slopes calculated from Figure 9b are given in Table S6. All the MOF derived catalysts show low Tafel slopes, ranged from $53 \mathrm{mV} \mathrm{dec}^{-1}$ to $64 \mathrm{mV} \mathrm{dec}^{-1}$. Obviously, the Tafel slope of Co-BTC-bipy-700 catalyst $\left(53 \mathrm{mV} \mathrm{dec}^{-1}\right)$ is the lowest. Compared with Pt/C whose Tafel slope is $74 \mathrm{mV} \mathrm{dec}{ }^{-1}$, the Co-BTC-bipy-700 catalyst exhibit more desirable ORR kinetics.

In order to figure out the role of the metal in Co-BTC-bipy-700 catalyst for ORR, cyanide anions $\left(\mathrm{CN}^{-}\right)$was used as a molecular probe to explore active ORR catalytic sites on Co-BTC-bipy-700 catalyst as they readily coordinate with the Co center. ${ }^{98}$ In addition, the control electrode of cobalt-covered RDE was prepared by electrodeposition. The cobalt covered RDE did not show catalytic activity for ORR (Figure S32a), indicating that metallic cobalt is not the active site for ORR, justifying that the contribution of metallic phase to catalytic performance can be ignored. After the addition of $\mathrm{CN}^{-}$, the onset potential and the diffusion-limiting current density of the ORR polarization curve of the Co-BTC-bipy-700 electrocatalyst decrease significantly (Figure S32b), suggesting the blocking of the cobalt sites in Co-BTC-bipy-700 catalyst by $\mathrm{CN}^{-}$ions. This behavior strongly suggests that cobalt in the M-N-C structure is directly involved in the ORR process. On the other hand, metals can catalyze the formation of $\mathrm{N}-\mathrm{C}$ and improve the degree of sp2-hybridized carbon and stabilized $\mathrm{N}$ structure in graphene framework based on XPS, Raman, CHN analysis, CVs and TEM results. All these results suggest that cobalt in M-N-C structure plays an important role in the ORR activity in both direct and indirect ways.

Another key reaction for rechargeable metal-air battery is the OER, ${ }^{47,99}$ corresponding to the charging process. The OER catalytic activity of Co-BTC-bipy-700, Pt/C and $\mathrm{IrO}_{2}$ were explored by LSV on RDE at a rotation speed of $1600 \mathrm{rpm}$ in $0.1 \mathrm{M} \mathrm{KOH}$. Compared to $\mathrm{Pt} / \mathrm{C}$ and $\mathrm{IrO}_{2}$ catalysts, Co-BTC-bipy-700 catalyst shows lower onset potential (1.54V vs. RHE) and lower potential at a current density of $10 \mathrm{~mA} \mathrm{~cm}{ }^{-2}(1.63 \mathrm{~V} v s$. RHE) as shown in Figure 10a. Based on Tafel plots obtained from Figure 10a, the Tafel slopes of Co-BTC-bipy-700 and Pt/C and

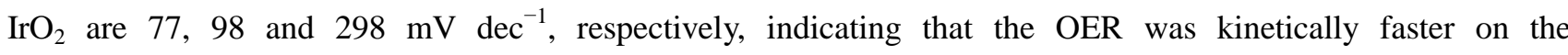
Co-BTC-bipy-700 catalyst. To assess the OER stability of catalysts, chronoamperometric test is carried out at $1.7 \mathrm{~V}$ 
vs. RHE. As shown in Figure 10c, $\mathrm{IrO}_{2}$ catalyst suffers a rapid current loss at the initial stage and the total current loss was about $66 \%$ after 24,000 s. On the contrary, more than $95 \%$ current can be remained for Co-BTC-bipy-700 catalyst, indicating a high stability for OER. After stability tests, there is no obviously change on the LSV for Co-BTC-bipy-700 catalyst (Figure 10d).

\section{Home-made Zn-air battery performance}

A home-made Zn-air battery was used to study the catalyst performance under real conditions. A Zn plate catalyst covered electrode and $6 \mathrm{M} \mathrm{KOH}$ with $0.2 \mathrm{M}$ zinc acetate solution were used as the anode, cathode and electrolyte, respectively. The open circuit voltage of Zn-air battery based on Co-BTC-bipy-700 catalysts is around $1.49 \mathrm{~V}$ (Figure S33). .Figure 11a presents the $i-V$ polarization curves of $\mathrm{Zn}$-air batteries based on different catalysts. The $\mathrm{Pt} / \mathrm{C}-\mathrm{IrO}_{2}$ (the mass ratio of the two catalysts is $1: 1$ ) mixed catalyst was chosen for comparison. Clearly, Co-BTC-bipy-700 shows higher polarization current density than $\mathrm{Pt} / \mathrm{C}-\mathrm{IrO}_{2}$ (Figure 11a), which benefits from better ORR and OER performance of Co-BTC-bipy-700. Moreover, the corresponding power density and current density during the discharging is shown in Figure 11b. The maximum power density of the assembled zinc-air battery based on Co-BTC-bipy-700 is determined to be $336 \mathrm{~mW} \mathrm{~cm}^{-2}$, which is higher than that of the zinc-air battery based on $\mathrm{Pt} / \mathrm{C}$ - $\mathrm{IrO}_{2}\left(270 \mathrm{~mW} \mathrm{~cm}^{-2}\right)$. In order to compare with previous works, the Tafel slop for each reaction and the overvoltage between ORR and OER $\left(E_{\mathrm{OER} @ 10 \mathrm{~mA} \mathrm{~cm}}{ }^{-2}-E_{\mathrm{ORR} @ 3 \mathrm{~mA} \mathrm{~cm}^{-2}}\right.$ base on the three-electrode system) is used as a descriptor for evaluating the bifunctional electrocatalytic activity of a catalyst (Table S8). The Co-BTC-bipy-700 catalyst shows that the value of $E_{\mathrm{OER} @ 10 \mathrm{~mA} \mathrm{~cm}^{-2}}-E_{\mathrm{ORR} @ 3 \mathrm{~mA} \mathrm{~cm}}{ }^{-2}$ reaches $0.84 \mathrm{~V}$, which is comparable with the highest level of bifunctional electrocatalysts reported recently (Table S8), including novel metal based catalysts, transition metal based catalysts, doped carbon based catalysts and metal-doped carbon based catalysts as well as other MOF-derived catalysts. Moreover, the comparison of the peak power densities of the $\mathrm{Zn}$-air battery based on the as-prepared 2D-CMO electrode in this work and those based on other electrodes reported in the literature is shown in Figure S34. Even if Co-BTC-bipy-700 is not the best ORR 
electrocatalyst, it surpasses most bifunctional electrocatalysts reported to date considering both ORR and OER, leading to the high $\mathrm{Zn}$-air battery performance. Compared with $\mathrm{Pt} / \mathrm{C}-\mathrm{IrO}_{2}$ catalyst, the Co-BTC-bipy-700 catalyst enables the Zn-air battery a higher voltage platform during the discharge process (benefiting from the high catalytic activity for ORR) and a lower voltage platform during the charge process (benefiting from the high catalytic activity for OER) at all the tested current densities (Figure 11c). At a current density of $3 \mathrm{~mA} \mathrm{~cm}{ }^{-2}$, the specific energy density of the Zn-air battery based on the Co-BTC-bipy-700 catalyst equals $1009.8 \mathrm{Wh} \mathrm{kg}^{-1}$ (based on the mass of $\mathrm{Zn}$ ), which is around $76.5 \%$ of the theoretical value $\left(1320 \mathrm{Wh} \mathrm{kg}^{-1}\right)$. Meanwhile, the specific energy density of the $\mathrm{Zn}$-air battery based on the whole system (including anode, electrolyte, cathode, and all other components of the device) is $4.37 \mathrm{Wh} \mathrm{kg}^{-1}$. Furthermore, long term charge-discharge tests were carried out with different catalysts. As shown in Figure S35, after 45 cycles, the degradation of the discharge voltage platform for $\mathrm{Zn}$-air batteries based on $\mathrm{Pt} / \mathrm{C}-\mathrm{IrO}_{2}$ and Co-BTC-bipy-700 catalysts are around $8 \%$. The decrease of catalyst performance is probably caused by the passivation of the zinc plate side and the corrosion of the carbon structure or the carbonate precipitation on the gas diffusion electrode side. ${ }^{100-103}$ The Zn-air battery based on Co-BTC-bipy-700 catalyst shows lower charging voltage and higher discharging voltage at all cycles than $\mathrm{Pt} / \mathrm{C}$ catalyst. In addition, the design diagram of the cell and the demonstration of the $\mathrm{Zn}$-air battery (based on Co-BTC-bipy-700) with an OCV of around 1.51 V are given in Figure S36.

\section{Conclusions}

In summary, a series of benzene-1,3,5-tricarboxylate (BTC) linker based MOFs have been successfully prepared via tailoring the pillars between the $2 \mathrm{D}$ layers and the metal ions. Subsequent pyrolysis leads to the formation of M-N-C composites catalysts. The influence of the MOFs unit, including linker and metal ions, on the resulting M-N-C catalyst performance for ORR were explored by a combination of DFT calculations, morphology and composition characterization, and electrochemical studies. It is found that (i) the key parameters (such as $\mathrm{N}$ content, 
significantly affected by the MOF units; (ii) Based on DFT computation, the Co- $\mathrm{N}_{\text {pyrid3 }}-\mathrm{C}, \mathrm{Co}-\mathrm{N}_{\mathrm{pyrid} 4}-\mathrm{C}$ and Co- $\mathrm{N}_{\text {pyrro2 }}-\mathrm{C}$ are the primary catalytically active sites for ORR in the Co-N-C structure; (iii) Metal particles in M-N-C structure play an important role for the ORR activity in both direct and indirect ways. Among the prepared catalysts, Co-BTC-bipy-700 exhibits high catalytic capacity for both ORR and OER, which is beneficial for rechargeable Zn-air battery. In battery tests, this catalyst exhibited higher discharge potential and lower charge potential than Pt/C catalyst. The specific energy density of Zn-air battery based on Co-BTC-bipy-700 catalyst was 1009.8 $\mathrm{Wh} \mathrm{kg}^{-1}$ at $3 \mathrm{~mA} \mathrm{~cm}{ }^{-2}$, which is around $76.5 \%$ of the theoretical energy density $\left(1320 \mathrm{Wh} \mathrm{kg}^{-1}\right)$. These results show that the catalytic capacity of M-N-C catalyst can be easily tailored by designable MOFs unit. It is still difficult to quantitatively control each key parameter of the M-N-C catalyst for chemical reactions. Fortunately, the present work could offer new guidelines for the molecular design of M-N-C catalysts, which are promising candidate catalysts for various reactions.

\section{Methods}

Electrodeposited MOFs: All MOFs were synthesized by anodic electrodeposition. Nickel plate (99.8\% purity, Goodfellow, UK). and cobalt plate (99.9\% purity, Goodfellow, UK) were carfully polished before used as an anode electrode. The cathode and anode material were the same. The metal plate was partially immersed in the different synthesis solutions. By applying a current for $8 \mathrm{~h}$, MOFs were grown on the surface of the metal plate. After completion of the MOF growth, the MOFs were carefully removed from the electrode. The resulting powder was washed with DMF and EtOH to remove excess ligand. The solution, temperature and current for the synthesis of different kinds of MOFs were as follows:

Ni(HBTC)(DMF) $)_{2}: \mathrm{Ni}(\mathrm{HBTC})(\mathrm{DMF})_{2}$ covered electrodes were synthesized in a solution containing $3 \mathrm{~g}$ 1,3,5-benzenetricarboxylic acid $\left(\mathrm{H}_{3} \mathrm{BTC}, 98 \%\right.$ purity $\mathrm{ABCR}$ Germany) per $100 \mathrm{~mL}$ solvent, including $67 \mathrm{~mL}$ N,N-dimethylformamide (DMF, $\geq 99 \%$ Chem-Lab) and $33 \mathrm{~mL}$ ethanol (EtOH, 99.9\% purity, VWR France), at a temperature of $120^{\circ} \mathrm{C}$ and a current density of $2 \mathrm{~mA} \mathrm{~cm}^{-2}$. 
Ni(HBTC)(4,4'-bipy): Ni(HBTC)(4,4'-bipy) covered electrodes were synthesized in a solution containing $3 \mathrm{~g}$ $\mathrm{H}_{3} \mathrm{BTC}$ and $1 \mathrm{~g}$ 4,4-dipyridyl (bipy, $98 \%$ purity ACROS ORGANIC) per $100 \mathrm{~mL}$ DMF at a temperature of $120{ }^{\circ} \mathrm{C}$ and a current density of $2 \mathrm{~mA} \mathrm{~cm}^{-2}$.

Co(HBTC)(4,4'-bipy): $\mathrm{Co}(\mathrm{HBTC})\left(4,4^{\prime}\right.$-bipy) covered electrodes were synthesized in a solution containing $3 \mathrm{~g}$ $\mathrm{H}_{3} \mathrm{BTC}$ and $1 \mathrm{~g}$ 4,4-dipyridyl per $100 \mathrm{~mL}$ DMF at three different temperatures $\left(30,60\right.$ and $\left.120{ }^{\circ} \mathrm{C}\right)$ and the current density of $2 \mathrm{~mA} \mathrm{~cm}^{-2}$.

Preparation of MOF derived $M-N-C$ catalyst: The different MOFs were pyrolized at $700{ }^{\circ} \mathrm{C}$ and $900{ }^{\circ} \mathrm{C}$ for $8 \mathrm{~h}$ in a nitrogen atmosphere with a flow rate of $300 \mathrm{~cm}^{3} \mathrm{~min}^{-1}$, respectively. The temperature inside the furnace was gradually increased from room temperature at a heating rate of $5{ }^{\circ} \mathrm{C} \min ^{-1}$. After pyrolysis, the sample was cooled down at a cooling rate of $5{ }^{\circ} \mathrm{C} \min ^{-1}$ in a flowing nitrogen atmosphere until room temperature. The as-prepared black powder was first washed with $30 \% \mathrm{H}_{2} \mathrm{SO}_{4}$ with ultrasound (half hour), then maintained at $60{ }^{\circ} \mathrm{C}$ overnight to remove uncovered (carbon) metal nanoparticles. The resulting samples were washed with DI water and EtOH repeatedly until $\mathrm{pH} \approx 6$, and then dried at $60{ }^{\circ} \mathrm{C}$. The preparation details of the different MOFs derived M-N-C catalysts are shown in Table S1.

Material characterizations: X-ray diffraction (XRD) patterns of the samples were recorded on a Bruker AXS D8 diffractometer using $\mathrm{Cu} \mathrm{K} \alpha$ radiation $(\lambda=0.15405 \mathrm{~nm})$ and $\mathrm{Ni}$ filter with $2 \theta$ ranging from $5^{\circ}$ to $30^{\circ}$ and a step size of $0.02^{\circ}$ ( $2 \mathrm{~s}$ per step). Thermogravimetric analysis (TGA) was performed in a nitrogen atmosphere on a thermogravimetric analyzer (AutoTGA 2950HR V5.4A, TA Instruments) using platinum pans at a heating rate of $5{ }^{\circ} \mathrm{C} \mathrm{min}^{-1}$. The onset temperature of the weight loss in the TGA was used as the decomposition temperature $\left(T_{\mathrm{d}}\right)$. The morphologies and structures of the samples were observed on a FEI/Philips XL30 FEG microscope (SEM). In order to improve the electronic conductivity of the MOF, the MOF-covered metal plate was sputtered with a $10 \mathrm{~nm}$ layer of Pt. High resolution transmission electron microscopy (HRTEM) and annular dark field (ADF) scanning transmission electron microscopy (STEM) images were obtained on an FEI Tecnai F20 field emission gun 
microscope operated at $200 \mathrm{kV}$ with a point-to-point resolution of $0.19 \mathrm{~nm}$, which is equipped with an annular dark field (ADF) and an electron energy loss spectroscopy (EELS) detectors. In addition, the obtained images and spectra were analyzed by Gatan Digital Micrograph software. X-ray photoelectron spectroscopy (XPS) was recorded with an ESCALAB250 (monochromatic Al Ka with $1486.6 \mathrm{eV}$ ). The binding energy was calibrated by placing the principal C1speak at $284.6 \mathrm{eV}$. CHN analyses were carried out on a Thermo Scientific Flash 2000 Organic Elemental Analyzer.

\section{Electrochemical characterizations:}

Preparation of working electrodes: All catalyst inks were prepared by dispersing $5 \mathrm{mg}$ of catalyst in $1 \mathrm{~mL}$ of isopropanol solvent containing $40 \mu \mathrm{L}$ of $5 \mathrm{wt} . \%$ Nafion (Alfa Aesar Germany) through sonication for $30 \mathrm{~min}$. Then, for the ORR test, $20 \mu \mathrm{L}$ of the catalyst ink was loaded onto a glass-carbon electrode (GCE) of $5 \mathrm{~mm}$ in diameter (loading: $0.50 \mathrm{mg} \mathrm{cm}^{-2}$ ). In order to reduce the influence of oxygen bubbles on the OER test caused by high mass loading, $10 \mu \mathrm{L}$ of the catalyst ink was loaded onto a glassy carbon electrode (GCE) of $5 \mathrm{~mm}$ in diameter (loading $0.25 \mathrm{mg} \mathrm{cm}^{-2}$ ). For comparison, multi-walled carbon nanotubes (MCNTs, Nanocyl, Belgium), Pt/C catalyst (10\% of platinum, Alfa Aesar Germany) and $\mathrm{IrO}_{2}$ (P40V020, particles from Premetek Co.) were conducted on the same electrochemical tests with the same mass loading. Here, the mass loading Pt is around $50 \mu \mathrm{g} \mathrm{cm}^{-2}$, which is higher than the "standard" loading $\left(20 \mu \mathrm{g} \mathrm{cm}^{-2}\right) .{ }^{36}$ In addition, the cobalt-covered electrode was electrodeposited at a current density of $-40 \mathrm{~mA} \mathrm{~cm}{ }^{-2}$ in $\mathrm{CoCl}_{2}\left(0.9 \mathrm{~mol} \mathrm{~L}^{-1}\right)$ aqueous solution with $\mathrm{LiClO}_{4}\left(0.1 \mathrm{~mol} \mathrm{~L}^{-1}\right)$ as the supporting electrolyte at room temperature until a mass loading of $0.50 \mathrm{mg} \mathrm{cm}^{-2}$ (based on Faraday's law) was obtained on the GCE. The details were shown in previous work. ${ }^{70,104}$ As the catalysts in this study are composite materials, electrochemical surface area (ECSA) measured by electrochemical double-layer capacitance or Brunauer-Emmett-Teller (BET) might lead to errors for current normalization. ${ }^{105}$ Therefore, the geometrical surface area of the GCE and constant catalyst mass loading for all catalysts were used as current normalization method. 
Catalytic performance: All the electrocatalytic measurements are carried out in a three-electrode cell using a rotating disk electrode (RDE, PINE Research Company). Before measuring, the electrolyte was purged with $\mathrm{O}_{2}$ (for ORR) or $\mathrm{N}_{2}$ (for OER) for at least 45 minutes. During the test, the electrolyte was continuously bubbled with $\mathrm{O}_{2}$ or $\mathrm{N}_{2}$. The ORR and OER catalytic performance of the samples were characterized by linear sweep voltammetry (LSV), cyclic voltammetry (CV) and electrochemical impedance spectroscopy (EIS) techniques on an Autolab electrochemical workstation at $25{ }^{\circ} \mathrm{C}$. An automatic thermostat bath was used to control the temperature (Julabo F25, Germany). The supporting electrolyte in all electrochemical experiments is $0.1 \mathrm{M} \mathrm{KOH}$. The currents of the LSV and CV are normalized by the mass of the active materials and the geometrical area of the glassy carbon electrode (GCE). The EIS measurements were recorded in a frequency range from $10^{-2}$ to $10^{4} \mathrm{~Hz}$ at open circuit potential with a peak-to-peak amplitude of $5 \mathrm{mV}$. The catalyst covered GCE, a graphite plate $(3.5 \mathrm{~cm} \times 5 \mathrm{~cm})$ and a $\mathrm{Hg} / \mathrm{HgO}$ electrode were used as the working electrode, the counter electrode and the reference electrode, respectively. All potentials are referred to the reversible hydrogen electrode (RHE) potential, which was converted from the $\mathrm{Hg} / \mathrm{HgO}$ electrode using the following equation:

$E_{R H E}=E_{H g / H g O}+0.098+0.059 \times \mathrm{pH}$

All potentials were iR-corrected to compensate for the influence of solution resistances, using the following equation $^{72,106,107}$ :

$E_{i R-\text { corrected }}=E-i R$

where $i$ is the current and $R$ is the uncompensated ohmic electrolyte resistance measured by EIS at high frequency.

Electrode kinetic data were calculated based on Koutecky-Levich $(\mathrm{K}-\mathrm{L})$ equation:

$\frac{1}{j}=\frac{1}{j_{L}}+\frac{1}{j_{K}}=\frac{1}{B \omega^{1 / 2}}+\frac{1}{n \mathrm{~F} k c_{\infty}}$

$B=0.62 n \mathrm{~F} D_{\circ}^{2 / 3} v^{-1 / 6} c_{\infty}$

where $j$ is the measured current density $\left(\mathrm{A} \mathrm{m}^{-2}\right), j_{\mathrm{L}}$ is the diffusion-limited current density $\left(\mathrm{A} \mathrm{m}^{-2}\right), j_{\mathrm{K}}$ is the kinetic current density $\left(\mathrm{A} \mathrm{m}^{-2}\right), \omega$ is the the angular velocity of the rotating electrode $\left(\mathrm{s}^{-1}\right), \mathrm{F}$ is the Faraday constant 
(96485 $\left.\mathrm{C} \mathrm{mol}^{-1}\right), c_{\infty}$ is the bulk concentration of $\mathrm{O}_{2}$ in $0.1 \mathrm{M} \mathrm{KOH}\left(1.2 \mathrm{~mol} \mathrm{~m}^{-3}\right), \mathrm{n}$ is the number of transferred electrons, $D_{\mathrm{o}}$ is the diffusion coefficient of $\mathrm{O}_{2}$ in $0.1 \mathrm{M} \mathrm{KOH}\left(1.9 \times 10^{-9} \mathrm{~m}^{2} \mathrm{~s}^{-1}\right)$, and $v$ is the kinematic viscosity of the electrolyte $\left(10^{-6} \mathrm{~m}^{2} \mathrm{~s}^{-1}\right)$, respectively. ${ }^{45,108,109}$

Rechargeable Zn-Air battery tests: For the full-cell test of our catalysts, we prepared a zinc plate as an anode, and $6 \mathrm{M} \mathrm{KOH}$ with $0.2 \mathrm{M}$ zinc acetate solution was used for the electrolyte (Figure S36). The different air cathodes were prepared by a mixture of different catalysts with $5 \mathrm{wt} \%$ Nafion solution with the same ratio for half reaction test (ORR and OER), and a mass loading of $3.5 \mathrm{mg} \mathrm{cm}^{-2}$ on a gas diffusion electrode (carbon fiber paper). All the $\mathrm{Zn}$-air batteries were tested under ambient atmosphere without a separator for anode and cathode. An assembled full-cell was characterized by chronopotentiometry (CP) at several charge and discharge currents.

First-principles calculations: All calculations were performed using plane-wave density functional theory (DFT) employing periodic boundary conditions as implemented in the VASP code ${ }^{110,}{ }^{111}$. The electronic exchange-correlation energy was modeled using the Perdew-Burke-Ernzerhof (PBE) functional ${ }^{112}$ within the generalized gradient approximation (GGA). The projector augmented wave (PAW) method was used to describe the ionic cores ${ }^{113,114}$. For the plane-wave expansion, a $550 \mathrm{eV}$ kinetic energy cut-off was used after testing a series of different cut-off energies. To model metal-nitrogen-carbon $(\mathrm{M}-\mathrm{N}-\mathrm{C})$ structures, the $(5 \times 5 \times 1)$ supercell $\mathrm{M}, \mathrm{N}$ co-doped graphene with lattice parameters of $a=b=12.28 \AA$ was constructed by a periodic boundary condition, and the vacuum layers were set to be larger than $20 \AA$ to avoid periodic interaction. A Monkhorst-Pack $3 \times 3 \times 1$ k-point grid was used to sample the Brillouin zone ${ }^{115}$. The convergence criterion for the electronic structure iteration was set to be $10^{-4} \mathrm{eV}$, and that for geometry optimizations were set to be $0.01 \mathrm{eV} / \mathrm{A}$ on force. To better describe the dispersion interaction within water adsorption systems, vdW correction was considered by adopting the Grimme's D2 scheme ${ }^{116}$.

In order to understand the mechanism and the active site of the oxygen reduction pathway on the M, N co-doped graphene, we use the free energy change $(G)$ for each ORR step as the criterion for assessing the ORR activity. 
Specifically, we considered the four-electron reaction pathway for ORR in alkaline media, as listed in Supplementary equations (2) to (5), which is the dominated mechanism for doped graphene catalysis ${ }^{117}$. The free-energy diagrams in the reaction pathways were calculated on the basis of a standard hydrogen electrode (CHE) model that was introduced by Nørskov et $a l^{118}$. For each step of ORR, the Gibbs free energy of formation is given by the following equation:

$\Delta G=\Delta E+\Delta Z P E-T \Delta S-\mathrm{e} U$

where $\triangle E, \triangle Z P E$, and $\Delta S$ are the changes of DFT total energy, zero-point energy, and entropy from the initial state to the finial state, respectively; $T$ is temperature; $\mathrm{U}$ is the electrode potential; e is the charge transfer. $\triangle Z P E$, and $\triangle S$ can be obtained by the thermodynamics table for gaseous molecules ${ }^{119}$ and by calculating the vibrational frequencies for the oxygenated intermediate (see Table S7), respectively. 


\section{References}

1. S. Enthaler, K. Junge and M. Beller, Sustainable metal catalysis with iron: from rust to a rising star? Angew Chem Int Ed Engl 2008, 47 (18), 3317-3321.

2. L. He, F. Weniger, H. Neumann and M. Beller, Synthesis, Characterization, and Application of Metal Nanoparticles Supported on Nitrogen-Doped Carbon: Catalysis beyond Electrochemistry. Angew Chem Int Ed Engl 2016, 55 (41), 12582-12594.

3. J. Yi, X. Liu, P. Liang, K. Wu, J. Xu, Y. Liu and J. Zhang, Non-noble Iron Group (Fe, Co, Ni)-Based Oxide Electrocatalysts for Aqueous Zinc-Air Batteries: Recent Progress, Challenges, and Perspectives. Organometallics 2018.

4. Y. Zhang, M. Zhang, L. Yang, G. Fan and F. Li, Enhanced base-catalyzed activity and structural stability of nitrogen-doped carbon modified $\mathrm{MgO}-\mathrm{MgFe}_{2} \mathrm{O}_{4}$ magnetic composites as catalysts for transesterification of tributyrin. Dalton Trans. 2017, 46 (19), 6324-6332.

5. X. Cui, A. E. Surkus, K. Junge, C. Topf, J. Radnik, C. Kreyenschulte and M. Beller, Highly selective hydrogenation of arenes using nanostructured ruthenium catalysts modified with a carbon-nitrogen matrix. Nat Commun 2016, 7, 11326.

6. G. H. Wang, Z. Cao, D. Gu, N. Pfander, A. C. Swertz, B. Spliethoff, H. J. Bongard, C. Weidenthaler, W. Schmidt, R. Rinaldi and F. Schuth, Nitrogen-Doped Ordered Mesoporous Carbon Supported Bimetallic PtCo Nanoparticles for Upgrading of Biophenolics. Angew Chem Int Ed Engl 2016, 55 (31), 8850-8855.

7. H. Yang, S. J. Bradley, A. Chan, G. I. Waterhouse, T. Nann, P. E. Kruger and S. G. Telfer, Catalytically Active Bimetallic Nanoparticles Supported on Porous Carbon Capsules Derived From Metal-Organic Framework Composites. J Am Chem Soc 2016, 138 (36), 11872-11881.

8. P. Liang, C. Zhang, X. Duan, H. Sun, S. Liu, M. O. Tade and S. Wang, An insight into metal organic framework derived $\mathrm{N}$-doped graphene for the oxidative degradation of persistent contaminants: formation mechanism and generation of singlet oxygen from peroxymonosulfate. Environ. Sci.: Nano 2017, 4 (2), 315-324.

9. S. Li, N. Yao, F. Zhao and X. Li, Nitrogen-doped carbon species: a promising nonmetallic promoter for the Co/SiO 2 Fischer-Tropsch synthesis catalyst. Catal. Sci. Technol. 2016, 6 (7), 2188-2194.

10. J. Lu, L. Yang, B. Xu, Q. Wu, D. Zhang, S. Yuan, Y. Zhai, X. Wang, Y. Fan and Z. Hu, Promotion effects of nitrogen doping into carbon nanotubes on supported iron Fischer-Tropsch catalysts for lower olefins. ACS Catal. 2014, 4 (2), 613-621.

11. J. Deng, P. Ren, D. Deng, L. Yu, F. Yang and X. Bao, Highly active and durable non-precious-metal catalysts encapsulated in carbon nanotubes for hydrogen evolution reaction. Energ. Environ. Sci. 2014, 7 (6), 1919.

12. S. Deng, Y. Zhong, Y. Zeng, Y. Wang, Z. Yao, F. Yang, S. Lin, X. Wang, X. Lu, X. Xia and J. Tu, Directional Construction of Vertical Nitrogen-Doped 1T-2H MoSe 2 /Graphene Shell/Core Nanoflake Arrays for Efficient Hydrogen Evolution Reaction. Adv Mater 2017.

13. H. Jin, J. Wang, D. Su, Z. Wei, Z. Pang and Y. Wang, In situ cobalt-cobalt oxide/N-doped carbon hybrids as superior bifunctional electrocatalysts for hydrogen and oxygen evolution. J Am Chem Soc 2015, 137 (7), 2688-2694.

14. H. W. Liang, S. Bruller, R. Dong, J. Zhang, X. Feng and K. Mullen, Molecular metal-Nx centres in porous carbon for electrocatalytic hydrogen evolution. Nat Commun 2015, 6, 7992.

15. J. Su, Y. Yang, G. Xia, J. Chen, P. Jiang and Q. Chen, Ruthenium-cobalt nanoalloys encapsulated in nitrogen-doped graphene as active electrocatalysts for producing hydrogen in alkaline media. Nat Commun 2017, 8,14969 .

16. A. Aijaz, J. Masa, C. Rosler, W. Xia, P. Weide, A. J. Botz, R. A. Fischer, W. Schuhmann and M. Muhler, $\mathrm{Co} @ \mathrm{Co}_{3} \mathrm{O}_{4}$ Encapsulated in Carbon Nanotube-Grafted Nitrogen-Doped Carbon Polyhedra as an Advanced 
Bifunctional Oxygen Electrode. Angew Chem Int Ed Engl 2016, 55 (12), 4087-4091.

17. C. Tang, H. S. Wang, H. F. Wang, Q. Zhang, G. L. Tian, J. Q. Nie and F. Wei, Spatially Confined Hybridization of Nanometer-Sized NiFe Hydroxides into Nitrogen-Doped Graphene Frameworks Leading to Superior Oxygen Evolution Reactivity. Adv Mater 2015.

18. J. Wang, K. Li, H. X. Zhong, D. Xu, Z. L. Wang, Z. Jiang, Z. J. Wu and X. B. Zhang, Synergistic Effect between Metal-Nitrogen-Carbon Sheets and $\mathrm{NiO}$ Nanoparticles for Enhanced Electrochemical Water-Oxidation Performance. Angew Chem Int Ed Engl 2015, 54 (36), 10530-10534.

19. Z. Wang, Y. Lu, Y. Yan, T. Y. P. Larissa, X. Zhang, D. Wuu, H. Zhang, Y. Yang and X. Wang, Core-shell carbon materials derived from metal-organic frameworks as an efficient oxygen bifunctional electrocatalyst. Nano Energy 2016, 30, 368-378.

20. A. Zhao, J. Masa, W. Xia, A. Maljusch, M. G. Willinger, G. Clavel, K. Xie, R. Schlogl, W. Schuhmann and M. Muhler, Spinel Mn-Co oxide in N-doped carbon nanotubes as a bifunctional electrocatalyst synthesized by oxidative cutting. J Am Chem Soc 2014, 136 (21), 7551-7554.

21. S. H. Ahn, X. Yu and A. Manthiram, "Wiring" Fe-Nx -Embedded Porous Carbon Framework onto 1D Nanotubes for Efficient Oxygen Reduction Reaction in Alkaline and Acidic Media. Adv Mater 2017.

22. G. A. Ferrero, K. Preuss, A. Marinovic, A. B. Jorge, N. Mansor, D. J. Brett, A. B. Fuertes, M. Sevilla and M. M. Titirici, Fe-N-Doped Carbon Capsules with Outstanding Electrochemical Performance and Stability for the Oxygen Reduction Reaction in Both Acid and Alkaline Conditions. ACS Nano 2016, 10 (6), 5922-5932.

23. Q. Jia, N. Ramaswamy, U. Tylus, K. Strickland, J. Li, A. Serov, K. Artyushkova, P. Atanassov, J. Anibal, C. Gumeci, S. C. Barton, M.-T. Sougrati, F. Jaouen, B. Halevi and S. Mukerjee, Spectroscopic insights into the nature of active sites in iron-nitrogen-carbon electrocatalysts for oxygen reduction in acid. Nano Energy 2016, $29,65-82$.

24. J. Li, S. Ghoshal, W. Liang, M.-T. Sougrati, F. Jaouen, B. Halevi, S. McKinney, G. McCool, C. Ma, X. Yuan, Z.-F. Ma, S. Mukerjee and Q. Jia, Structural and mechanistic basis for the high activity of Fe-N-C catalysts toward oxygen reduction. Energy Environ. Sci. 2016, 9 (7), 2418-2432.

25. H. W. Liang, W. Wei, Z. S. Wu, X. Feng and K. Mullen, Mesoporous metal-nitrogen-doped carbon electrocatalysts for highly efficient oxygen reduction reaction. J Am Chem Soc 2013, 135 (43), 16002-16005.

26. L. Lin, Q. Zhu and A. W. Xu, Noble-metal-free Fe-N/C catalyst for highly efficient oxygen reduction reaction under both alkaline and acidic conditions. J Am Chem Soc 2014, 136 (31), 11027-11033.

27. C.-Y. Su, H. Cheng, W. Li, Z.-Q. Liu, N. Li, Z. Hou, F.-Q. Bai, H.-X. Zhang and T.-Y. Ma, Atomic Modulation of FeCo-Nitrogen-Carbon Bifunctional Oxygen Electrodes for Rechargeable and Flexible All-Solid-State Zinc-Air Battery. Adv. Energy Mater. 2017, 1602420.

28. J. Xiao, Y. Xu, Y. Xia, J. Xi and S. Wang, Ultra-small $\mathrm{Fe}_{2} \mathrm{~N}$ nanocrystals embedded into mesoporous nitrogen-doped graphitic carbon spheres as a highly active, stable, and methanol-tolerant electrocatalyst for the oxygen reduction reaction. Nano Energy 2016, 24, 121-129.

29. P. P. Sharma, J. Wu, R. M. Yadav, M. Liu, C. J. Wright, C. S. Tiwary, B. I. Yakobson, J. Lou, P. M. Ajayan and X. D. Zhou, Nitrogen-Doped Carbon Nanotube Arrays for High-Efficiency Electrochemical Reduction of CO2: On the Understanding of Defects, Defect Density, and Selectivity. Angew Chem Int Ed Engl 2015, 54 (46), 13701-13705.

30. A. S. Varela, N. Ranjbar Sahraie, J. Steinberg, W. Ju, H. S. Oh and P. Strasser, Metal-Doped Nitrogenated Carbon as an Efficient Catalyst for Direct $\mathrm{CO}_{2}$ Electroreduction to $\mathrm{CO}$ and Hydrocarbons. Angew Chem Int Ed Engl 2015, 54 (37), 10758-10762.

31. M. Mahyari and A. Shaabani, Nickel nanoparticles immobilized on three-dimensional nitrogen-doped graphene as a superb catalyst for the generation of hydrogen from the hydrolysis of ammonia borane. J. Mater. Chem. A 2014, 2 (39), 16652-16659. 
32. D. Chu and R. Jiang, Novel electrocatalysts for direct methanol fuel cells. Solid State Ionics 2002, 148 (3), 591-599.

33. H. Schulenburg, S. Stankov, V. Schünemann, J. Radnik, I. Dorbandt, S. Fiechter, P. Bogdanoff and H. Tributsch, Catalysts for the oxygen reduction from heat-treated iron (III) tetramethoxyphenylporphyrin chloride: structure and stability of active sites. The Journal of Physical Chemistry B 2003, 107 (34), 9034-9041.

34. H. Peng, F. Liu, X. Liu, S. Liao, C. You, X. Tian, H. Nan, F. Luo, H. Song, Z. Fu and P. Huang, Effect of Transition Metals on the Structure and Performance of the Doped Carbon Catalysts Derived From Polyaniline and Melamine for ORR Application. ACS Catal. 2014, 4 (10), 3797-3805.

35. J. Wang and F. Ciucci, Boosting Bifunctional Oxygen Electrolysis for N-Doped Carbon via Bimetal Addition. Small 2017, 13 (16).

36. G. Wu, K. L. More, C. M. Johnston and P. Zelenay, High-performance electrocatalysts for oxygen reduction derived from polyaniline, iron, and cobalt. Science 2011, 332 (6028), 443-447.

37. Z. Li, G. Li, L. Jiang, J. Li, G. Sun, C. Xia and F. Li, Ionic liquids as precursors for efficient mesoporous iron-nitrogen-doped oxygen reduction electrocatalysts. Angew Chem Int Ed Engl 2015, 54 (5), 1494-1498.

38. L. Osmieri, A. H. A. Monteverde Videla, M. Armandi and S. Specchia, Influence of different transition metals on the properties of $\mathrm{Me}-\mathrm{N}-\mathrm{C}(\mathrm{Me}=\mathrm{Fe}, \mathrm{Co}, \mathrm{Cu}, \mathrm{Zn})$ catalysts synthesized using SBA-15 as tubular nano-silica reactor for oxygen reduction reaction. Int. J. Hydrog. Energy 2016, 41 (47), 22570-22588.

39. Y. J. Sa, D. J. Seo, J. Woo, J. T. Lim, J. Y. Cheon, S. Y. Yang, J. M. Lee, D. Kang, T. J. Shin, H. S. Shin, H. Y. Jeong, C. S. Kim, M. G. Kim, T. Y. Kim and S. H. Joo, A General Approach to Preferential Formation of Active Fe-Nx Sites in Fe-N/C Electrocatalysts for Efficient Oxygen Reduction Reaction. J Am Chem Soc 2016, 138 (45), 15046-15056.

40. Y. Z. Chen, C. Wang, Z. Y. Wu, Y. Xiong, Q. Xu, S. H. Yu and H. L. Jiang, From Bimetallic Metal-Organic Framework to Porous Carbon: High Surface Area and Multicomponent Active Dopants for Excellent Electrocatalysis. Adv Mater 2015, 27 (34), 5010-5016.

41. Q. Li, P. Xu, W. Gao, S. Ma, G. Zhang, R. Cao, J. Cho, H. L. Wang and G. Wu, Graphene/graphene-tube nanocomposites templated from cage-containing metal-organic frameworks for oxygen reduction in $\mathrm{Li}-\mathrm{O}(2)$ batteries. Adv Mater 2014, 26 (9), 1378-1386.

42. S. Ma, G. A. Goenaga, A. V. Call and D. J. Liu, Cobalt imidazolate framework as precursor for oxygen reduction reaction electrocatalysts. Chemistry 2011, 17 (7), 2063-2067.

43. X. Li, Y. Fang, X. Lin, M. Tian, X. An, Y. Fu, R. Li, J. Jin and J. Ma, MOF derived $\mathrm{Co}_{3} \mathrm{O}_{4}$ nanoparticles embedded in N-doped mesoporous carbon layer/MWCNT hybrids: extraordinary bi-functional electrocatalysts for OER and ORR. J. Mater. Chem. A 2015, 3 (33), 17392-17402.

44. W. Xia, R. Zou, L. An, D. Xia and S. Guo, A metal-organic framework route to in situ encapsulation of $\mathrm{Co} @ \mathrm{Co}_{3} \mathrm{O}_{4} @ \mathrm{C}$ core@bishell nanoparticles into a highly ordered porous carbon matrix for oxygen reduction. Energy Environ. Sci. 2015, 8 (2), 568-576.

45. X. Wang, J. Zhou, H. Fu, W. Li, X. Fan, G. Xin, J. Zheng and X. Li, MOF derived catalysts for electrochemical oxygen reduction. J. Mater. Chem. A 2014, 2 (34), 14064-14070.

46. B. You, N. Jiang, M. Sheng, S. Gul, J. Yano and Y. Sun, High-Performance Overall Water Splitting Electrocatalysts Derived from Cobalt-Based Metal-Organic Frameworks. Chem. Mater. 2015, 27 (22), 7636-7642.

47. B. Y. Xia, Y. Yan, N. Li, H. B. Wu, X. W. Lou and X. Wang, A metal-organic framework-derived bifunctional oxygen electrocatalyst. Nature Energy 2016, 1 (1), 15006.

48. A. Morozan, M. T. Sougrati, V. Goellner, D. Jones, L. Stievano and F. Jaouen, Effect of Furfuryl Alcohol on Metal Organic Framework-based Fe/N/C Electrocatalysts for Polymer Electrolyte Membrane Fuel Cells. Electrochim. Acta 2014, 119, 192-205. 
49. A. Morozan, V. Goellner, Y. Nedellec, J. Hannauer and F. Jaouen, Effect of the Transition Metal on Metal-Nitrogen-Carbon Catalysts for the Hydrogen Evolution Reaction. J. Electrochem. Soc. 2015, 162 (9), H719-H726.

50. J. S. Li, S. L. Li, Y. J. Tang, M. Han, Z. H. Dai, J. C. Bao and Y. Q. Lan, Nitrogen-doped Fe/Fe $\mathrm{C}_{3} @$ graphitic layer/carbon nanotube hybrids derived from MOFs: efficient bifunctional electrocatalysts for ORR and OER. Chem Commun (Camb) 2015, 51 (13), 2710-2713.

51. J.-S. Li, Y.-J. Tang, C.-H. Liu, S.-L. Li, R.-H. Li, L.-Z. Dong, Z.-H. Dai, J.-C. Bao and Y.-Q. Lan, Polyoxometalate-based metal-organic framework-derived hybrid electrocatalysts for highly efficient hydrogen evolution reaction. J. Mater. Chem. A 2016, 4 (4), 1202-1207.

52. S. Zhao, H. Yin, L. Du, L. He, K. Zhao, L. Chang, G. Yin, H. Zhao, S. Liu and Z. Tang, Carbonized Nanoscale Metal-Organic Frameworks as High Performance Electrocatalyst for Oxygen Reduction Reaction. ACS Nano 2014, 8 (12), 12660-12668.

53. H. Zhong, Y. Luo, S. He, P. Tang, D. Li, N. Alonso-Vante and Y. Feng, Electrocatalytic Cobalt Nanoparticles Interacting with Nitrogen-Doped Carbon Nanotube in Situ Generated from a Metal-Organic Framework for the Oxygen Reduction Reaction. ACS Appl Mater Interfaces 2017, 9 (3), 2541-2549.

54. A. Kong, C. Mao, Q. Lin, X. Wei, X. Bu and P. Feng, From cage-in-cage MOF to N-doped and Co-nanoparticle-embedded carbon for oxygen reduction reaction. Dalton Trans 2015, 44 (15), 6748-6754.

55. M. Zhang, Q. Dai, H. Zheng, M. Chen and L. Dai, Novel MOF-Derived Co@N-C Bifunctional Catalysts for Highly Efficient Zn-Air Batteries and Water Splitting. Adv Mater 2018, 30 (10).

56. R. A. Fischer, Metal-organic frameworks--the new jack of all trades for (inorganic) chemists. Angew Chem Int Ed Engl 2014, 53 (23), 5716-5717.

57. M. Peplow, The hole story. Nature 2015, 520 (7546), 148.

58. G. Fu, Z. Cui, Y. Chen, Y. Li, Y. Tang and J. B. Goodenough, $\mathrm{Ni}_{3} \mathrm{Fe}-\mathrm{N}$ Doped Carbon Sheets as a Bifunctional Electrocatalyst for Air Cathodes. Adv. Energy Mater. 2017, 7 (1), 1601172.

59. X. Han, X. Wu, C. Zhong, Y. Deng, N. Zhao and W. Hu, NiCo $\mathrm{S}_{4}$ nanocrystals anchored on nitrogen-doped carbon nanotubes as a highly efficient bifunctional electrocatalyst for rechargeable zinc-air batteries. Nano Energy 2017, 31, 541-550.

60. J.-S. Lee, G. Nam, J. Sun, S. Higashi, H.-W. Lee, S. Lee, W. Chen, Y. Cui and J. Cho, Composites of a Prussian Blue Analogue and Gelatin-Derived Nitrogen-Doped Carbon-Supported Porous Spinel Oxides as Electrocatalysts for a Zn-Air Battery. Adv. Energy Mater. 2016, 6 (22), 1601052.

61. L. Li, S. Liu and A. Manthiram, $\mathrm{Co}_{3} \mathrm{O}_{4}$ nanocrystals coupled with O- and N-doped carbon nanoweb as a synergistic catalyst for hybrid Li-air batteries. Nano Energy 2015, 12, 852-860.

62. A. Khor, P. Leung, M. R. Mohamed, C. Flox, Q. Xu, L. An, R. G. A. Wills, J. R. Morante and A. A. Shah, Review of zinc-based hybrid flow batteries: From fundamentals to applications. Materials Today Energy 2018, 8 , 80-108.

63. A. Mahmood, W. Guo, H. Tabassum and R. Zou, Metal-Organic Framework-Based Nanomaterials for Electrocatalysis. Adv. Energy Mater. 2016, 6 (17), 1600423.

64. J. Masa, W. Xia, M. Muhler and W. Schuhmann, On the Role of Metals in Nitrogen-Doped Carbon Electrocatalysts for Oxygen Reduction. Angew. Chem. Int. Edit. 2015, 54 (35), 10102-10120.

65. Z. Xia, L. An, P. Chen and D. Xia, Non-Pt Nanostructured Catalysts for Oxygen Reduction Reaction: Synthesis, Catalytic Activity and its Key Factors. Adv. Energy Mater. 2016, 6 (17), 1600458.

66. C. Zhu, H. Li, S. Fu, D. Du and Y. Lin, Highly efficient nonprecious metal catalysts towards oxygen reduction reaction based on three-dimensional porous carbon nanostructures. Chem Soc Rev 2016, 45 (3), 517-531.

67. Y. Li, L. Xie, Y. Liu, R. Yang and X. Li, Favorable hydrogen storage properties of M (HBTC)(4, 4'-bipy). 3DMF (M= Ni and Co). Inorganic chemistry 2008, 47 (22), 10372-10377. 
68. H. Al-Kutubi, J. Gascon, E. J. R. Sudhölter and L. Rassaei, Electrosynthesis of Metal-Organic Frameworks: Challenges and Opportunities. ChemElectroChem 2015, 2 (4), 462-474.

69. R. Ameloot, L. Stappers, J. Fransaer, L. Alaerts, B. F. Sels and D. E. De Vos, Patterned Growth of Metal-Organic Framework Coatings by Electrochemical Synthesis. Chem. Mater. 2009, 21 (13), 2580-2582.

70. X. Zhang, J. Luo, P. Tang, X. Ye, X. Peng, H. Tang, S.-G. Sun and J. Fransaer, A universal strategy for metal oxide anchored and binder-free carbon matrix electrode: A supercapacitor case with superior rate performance and high mass loading. Nano Energy 2017, 31, 311-321.

71. J. Zhou, Z. Zhang, W. Xing, J. Yu, G. Han, W. Si and S. Zhuo, Nitrogen-doped hierarchical porous carbon materials prepared from meta-aminophenol formaldehyde resin for supercapacitor with high rate performance. Electrochim. Acta 2015, 153, 68-75.

72. L. Ge, Y. Yang, L. Wang, W. Zhou, R. De Marco, Z. Chen, J. Zou and Z. Zhu, High activity electrocatalysts from metal-organic framework-carbon nanotube templates for the oxygen reduction reaction. Carbon 2015, 82, 417-424.

73. A. Moisala, A. G. Nasibulin and E. I. Kauppinen, The role of metal nanoparticles in the catalytic production of single-walled carbon nanotubes_a review. Journal of Physics: condensed matter 2003, 15 (42), S3011.

74. A. Kudashov, A. Okotrub, L. Bulusheva, I. Asanov, Y. V. Shubin, N. Yudanov, L. Yudanova, V. Danilovich and O. Abrosimov, Influence of $\mathrm{Ni}-\mathrm{Co}$ catalyst composition on nitrogen content in carbon nanotubes. The Journal of Physical Chemistry B 2004, 108 (26), 9048-9053.

75. J. B. Gilbert, M. F. Rubner and R. E. Cohen, Depth-profiling X-ray photoelectron spectroscopy (XPS) analysis of interlayer diffusion in polyelectrolyte multilayers. Proc Natl Acad Sci U S A 2013, 110 (17), 6651-6656.

76. J. C. Vickerman and I. Gilmore, Surface analysis: the principal techniques, John Wiley \& Sons, 2011.

77. Z. Li, G. Li, X. Chen, Z. Xia, J. Yao, B. Yang, L. Lei and Y. Hou, Water Splitting-Biosynthetic Hybrid System for $\mathrm{CO}_{2}$ Conversion using Nickel Nanoparticles Embedded in N-Doped Carbon Nanotubes. ChemSusChem 2018, 11 (14), 2382-2387.

78. C. Wang, Y. Wang, H. Yang, Y. Zhang, H. Zhao and Q. Wang, Revealing the Role of Electrocatalyst Crystal Structure on Oxygen Evolution Reaction with Nickel as an Example. Small 2018, 14 (40), e1802895.

79. Y. Xu, W. Tu, B. Zhang, S. Yin, Y. Huang, M. Kraft and R. Xu, Nickel Nanoparticles Encapsulated in Few-Layer Nitrogen-Doped Graphene Derived from Metal-Organic Frameworks as Efficient Bifunctional Electrocatalysts for Overall Water Splitting. Adv Mater 2017, 29 (11).

80. Y. Yao, C. Lian, G. Wu, Y. Hu, F. Wei, M. Yu and S. Wang, Synthesis of "sea urchin"-like carbon nanotubes/porous carbon superstructures derived from waste biomass for treatment of various contaminants. Applied Catalysis B: Environmental 2017, 219, 563-571.

81. Q. Cheng, S. Han, K. Mao, C. Chen, L. Yang, Z. Zou, M. Gu, Z. Hu and H. Yang, Co nanoparticle embedded in atomically-dispersed Co-N-C nanofibers for oxygen reduction with high activity and remarkable durability. Nano Energy 2018, 52, 485-493.

82. M. Li, T. Liu, X. Bo, M. Zhou and L. Guo, A novel flower-like architecture of FeCo@NC-functionalized ultra-thin carbon nanosheets as a highly efficient 3D bifunctional electrocatalyst for full water splitting. J. Mater. Chem. A 2017, 5 (11), 5413-5425.

83. C. Yang, L. Fu, R. Zhu and Z. Liu, Influence of cobalt species on the catalytic performance of $\mathrm{Co}-\mathrm{N}-\mathrm{C} / \mathrm{SiO} 2$ for ethylbenzene oxidation. Physical chemistry chemical physics : PCCP 2016, 18 (6), 4635-4642.

84. J. Yang, D.-J. Liu, N. N. Kariuki and L. X. Chen, Aligned carbon nanotubes with built-in FeN4active sites for electrocatalytic reduction of oxygen. Chem. Commun. 2008, (3), 329-331.

85. N. P. Subramanian, X. Li, V. Nallathambi, S. P. Kumaraguru, H. Colon-Mercado, G. Wu, J.-W. Lee and B. N. Popov, Nitrogen-modified carbon-based catalysts for oxygen reduction reaction in polymer electrolyte membrane fuel cells. J. Power Sources 2009, 188 (1), 38-44. 
86. K. Wan, G.-F. Long, M.-Y. Liu, L. Du, Z.-X. Liang and P. Tsiakaras, Nitrogen-doped ordered mesoporous carbon: synthesis and active sites for electrocatalysis of oxygen reduction reaction. Applied Catalysis B: Environmental 2015, 165, 566-571.

87. J. Verbeeck and S. Van Aert, Model based quantification of EELS spectra. Ultramicroscopy 2004, 101 (2-4), 207-224.

88. W. J. Jiang, L. Gu, L. Li, Y. Zhang, X. Zhang, L. J. Zhang, J. Q. Wang, J. S. Hu, Z. Wei and L. J. Wan, Understanding the High Activity of Fe-N-C Electrocatalysts in Oxygen Reduction: $\mathrm{Fe} / \mathrm{Fe}_{3} \mathrm{C}$ Nanoparticles Boost the Activity of Fe-N(x). J Am Chem Soc 2016, 138 (10), 3570-3578.

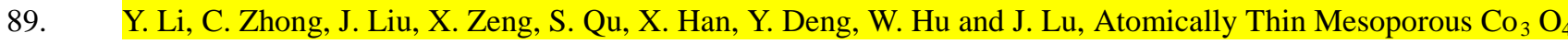
Layers Strongly Coupled with N-rGO Nanosheets as High-Performance Bifunctional Catalysts for 1D Knittable Zinc-Air Batteries. Adv Mater 2018, 30 (4).

90. S. Kattel, P. Atanassov and B. Kiefer, Catalytic activity of Co-N(x)/C electrocatalysts for oxygen reduction reaction: a density functional theory study. Physical chemistry chemical physics : PCCP 2013, 15 (1), 148-153.

91. F. Li, H. Shu, C. Hu, Z. Shi, X. Liu, P. Liang and X. Chen, Atomic Mechanism of Electrocatalytically Active Co-N Complexes in Graphene Basal Plane for Oxygen Reduction Reaction. ACS Appl Mater Interfaces 2015, 7 (49), 27405-27413.

92. G.-L. Chai, K. Qiu, M. Qiao, M.-M. Titirici, C. Shang and Z. Guo, Active sites engineering leads to exceptional ORR and OER bifunctionality in P,N Co-doped graphene frameworks. Energ. Environ. Sci. 2017, 10 (5), 1186-1195.

93. Y.-N. Chen, X. Zhang, H. Cui, X. Zhang, Z. Xie, X.-G. Wang, M. Jiao and Z. Zhou, Synergistic electrocatalytic oxygen reduction reactions of $\mathrm{Pd} / \mathrm{B} 4 \mathrm{C}$ for ultra-stable Zn-air batteries. Energy Storage Materials 2018, 15, 226-233.

94. Y. Liu, J. Chung, Y. Jang, S. Mao, B. M. Kim, Y. Wang and X. Guo, Magnetically recoverable nanoflake-shaped iron oxide/Pt heterogeneous catalysts and their excellent catalytic performance in the hydrogenation reaction. ACS Appl Mater Interfaces 2014, 6 (3), 1887-1892.

95. V. Polshettiwar, R. Luque, A. Fihri, H. Zhu, M. Bouhrara and J. M. Basset, Magnetically recoverable nanocatalysts. Chem Rev 2011, 111 (5), 3036-3075.

96. S. Wittmann, A. Schatz, R. N. Grass, W. J. Stark and O. Reiser, A recyclable nanoparticle-supported palladium catalyst for the hydroxycarbonylation of aryl halides in water. Angew Chem Int Ed Engl 2010, 49 (10), 1867-1870.

97. W. Niu, Z. Li, K. Marcus, L. Zhou, Y. Li, R. Ye, K. Liang and Y. Yang, Surface-Modified Porous Carbon Nitride Composites as Highly Efficient Electrocatalyst for Zn-Air Batteries. Adv. Energy Mater. 2018, 8 (1), 1701642.

98. S. Gupta, C. Fierro and E. Yeager, The effects of cyanide on the electrochemical properties of transition metal macrocycles for oxygen reduction in alkaline solutions. J Electroanal Chem Interfacial Electrochem 1991, 306 (1-2), 239-250.

99. Z.-F. Huang, J. Wang, Y. Peng, C.-Y. Jung, A. Fisher and X. Wang, Design of Efficient Bifunctional Oxygen Reduction/Evolution Electrocatalyst: Recent Advances and Perspectives. Advanced Energy Materials 2017, 7 (23), 1700544.

100. J. Yi, P. Liang, X. Liu, K. Wu, Y. Liu, Y. Wang, Y. Xia and J. Zhang, Challenges, mitigation strategies and perspectives in development of zinc-electrode materials and fabrication for rechargeable zinc-air batteries. Energ. Environ. Sci. 2018, 11 (11), 3075-3095.

101. K. Jayasayee, J. A. R. V. Veen, T. G. Manivasagam, S. Celebi, E. J. M. Hensen and F. A. de Bruijn, Oxygen reduction reaction $(\mathrm{ORR})$ activity and durability of carbon supported $\mathrm{PtM}(\mathrm{Co}, \mathrm{Ni}, \mathrm{Cu})$ alloys: Influence of particle size and non-noble metals. Applied Catalysis B: Environmental 2012, 111-112, 515-526.

102. I. Roche, E. Chaînet, M. Chatenet and J. Vondrák, Carbon-supported manganese oxide nanoparticles as 
electrocatalysts for the oxygen reduction reaction (ORR) in alkaline medium: physical characterizations and ORR mechanism. The Journal of Physical Chemistry C 2007, 111 (3), 1434-1443.

103. X. Wang, W. Li, Z. Chen, M. Waje and Y. Yan, Durability investigation of carbon nanotube as catalyst support for proton exchange membrane fuel cell. J. Power Sources 2006, 158 (1), 154-159.

104. C. Cui, S. Jiang and A. Tseung, Electrodeposition of cobalt from aqueous chloride solutions. J. Electrochem. Soc. 1990, 137 (11), 3418-3423.

105. S. Anantharaj, S. R. Ede, K. Sakthikumar, K. Karthick, S. Mishra and S. Kundu, Recent Trends and Perspectives in Electrochemical Water Splitting with an Emphasis on Sulfide, Selenide, and Phosphide Catalysts of Fe, Co, and Ni: A Review. ACS Catal. 2016, 6 (12), 8069-8097.

106. F. Liang, Y. Yu, W. Zhou, X. Xu and Z. Zhu, Highly defective $\mathrm{CeO}_{2}$ as a promoter for efficient and stable water oxidation. J. Mater. Chem. A 2015, 3 (2), 634-640.

107. R. Liu, F. Liang, W. Zhou, Y. Yang and Z. Zhu, Calcium-doped lanthanum nickelate layered perovskite and nickel oxide nano-hybrid for highly efficient water oxidation. Nano Energy 2015, 12, 115-122.

108. Y. Hou, T. Huang, Z. Wen, S. Mao, S. Cui and J. Chen, Metal-Organic Framework-Derived Nitrogen-Doped Core-Shell-Structured Porous Fe/Fe3C@C Nanoboxes Supported on Graphene Sheets for Efficient Oxygen Reduction Reactions. Adv. Energy Mater. 2014, 4 (11), 1400337.

109. H. X. Zhong, J. Wang, Y. W. Zhang, W. L. Xu, W. Xing, D. Xu, Y. F. Zhang and X. B. Zhang, ZIF-8 derived graphene-based nitrogen-doped porous carbon sheets as highly efficient and durable oxygen reduction electrocatalysts. Angew Chem Int Ed Engl 2014, 53 (51), 14235-14239.

110. G. Kresse and J. Furthmüller, Efficient iterative schemes for Itextit $\{a b$ initio $\}$ total-energy calculations using a plane-wave basis set. Physical Review B 1996, 54 (16), 11169-11186.

111. G. Kresse and J. Furthmüller, Efficiency of ab-initio total energy calculations for metals and semiconductors using a plane-wave basis set. Computational Materials Science 1996, 6 (1), 15-50.

112. J. P. Perdew, K. Burke and M. Ernzerhof, Generalized Gradient Approximation Made Simple. Physical Review Letters 1996, 77 (18), 3865-3868.

113. P. E. Blöchl, Projector augmented-wave method. Physical Review B 1994, 50 (24), 17953-17979.

114. G. Kresse and D. Joubert, From ultrasoft pseudopotentials to the projector augmented-wave method. Physical Review B 1999, 59 (3), 1758-1775.

115. H. J. Monkhorst and J. D. Pack, Special points for Brillouin-zone integrations. Physical Review B 1976, 13 (12), 5188-5192.

116. S. Grimme, Semiempirical GGA-type density functional constructed with a long-range dispersion correction. Journal of Computational Chemistry 2006, 27 (15), 1787-1799.

117. J. Zhang, Z. Zhao, Z. Xia and L. Dai, A metal-free bifunctional electrocatalyst for oxygen reduction and oxygen evolution reactions. Nature Nanotechnology 2015, 10, 444.

118. J. Rossmeisl, Z. W. Qu, H. Zhu, G. J. Kroes and J. K. Nørskov, Electrolysis of water on oxide surfaces. Journal of Electroanalytical Chemistry 2007, 607 (1), 83-89.

119. M. W. J. Chase, NIST-JANAF Thermochemical Tables American Institute of Physics: New York 1998.

\section{Competing financial interests}

The authors declare no competing financial interests. 


\section{Figures \& Tables}

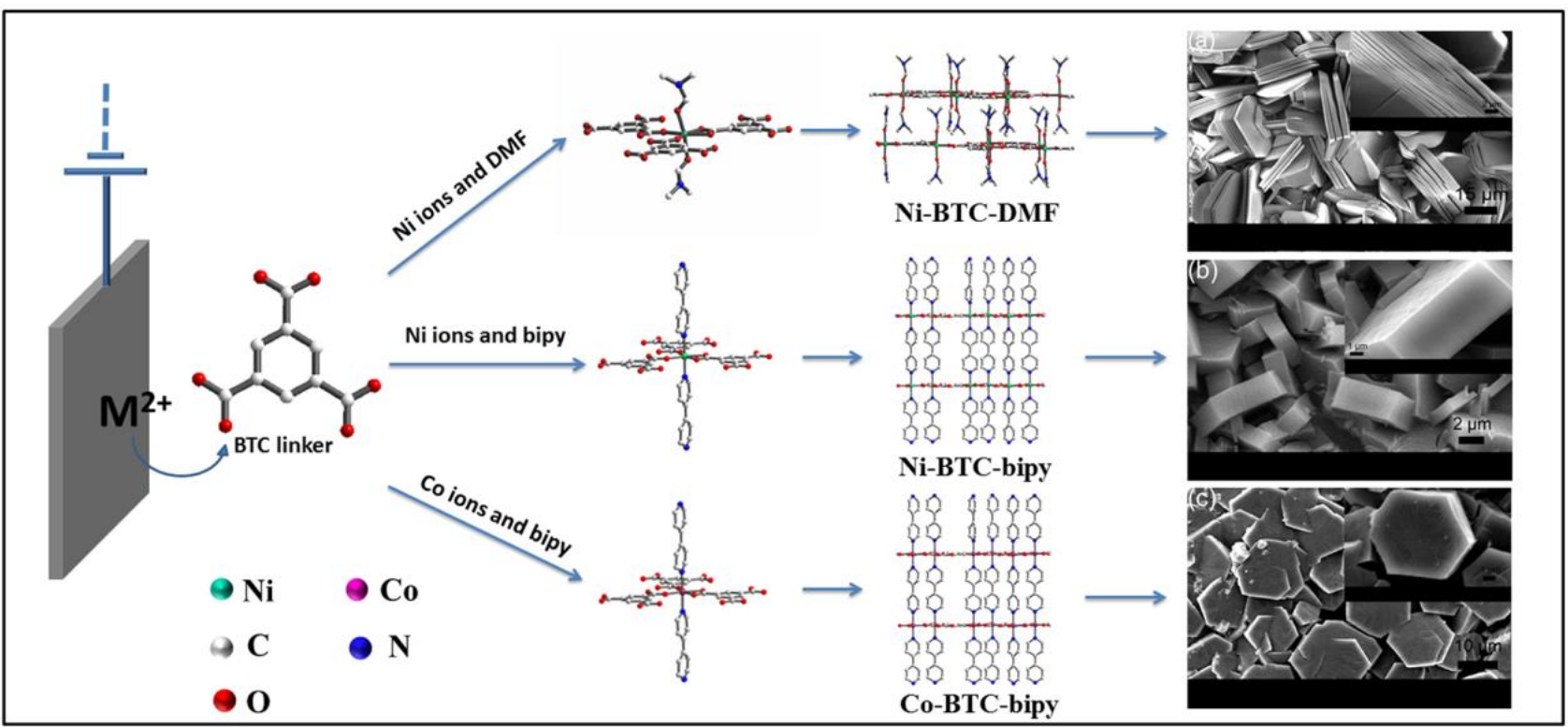

Figure 1. Schematic illustration of the synthesis of MOFs on substrates, schematic views of the crystal structures showing the coordinative environments around the center metal atoms in Ni-BTC-DMF, Ni-BTC-bipy and Co-BTC-bipy (all $\mathrm{H}$ atoms are omitted for clarity), and view of supramolecular frameworks from the $b$ axis. SEM images of (a) Ni-BTC-DMF, (b) Ni-BTC-bipy and (c) Co-BTC-bipy electrodeposited on substrates are also given. 
(a)

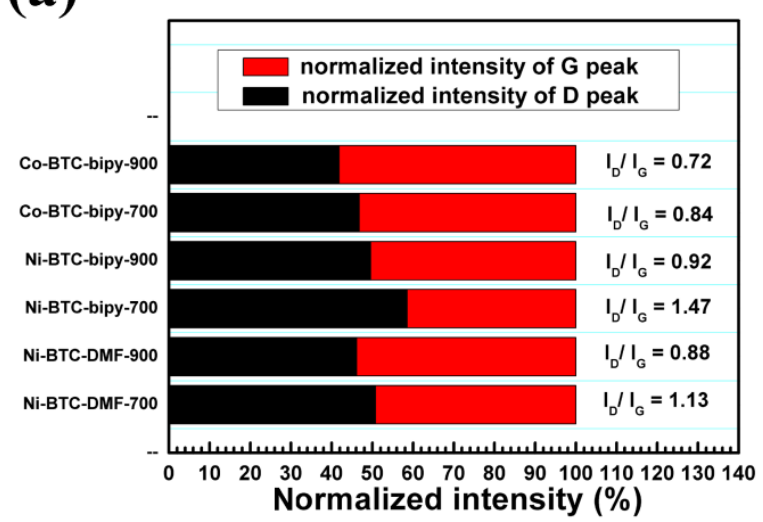

(b)

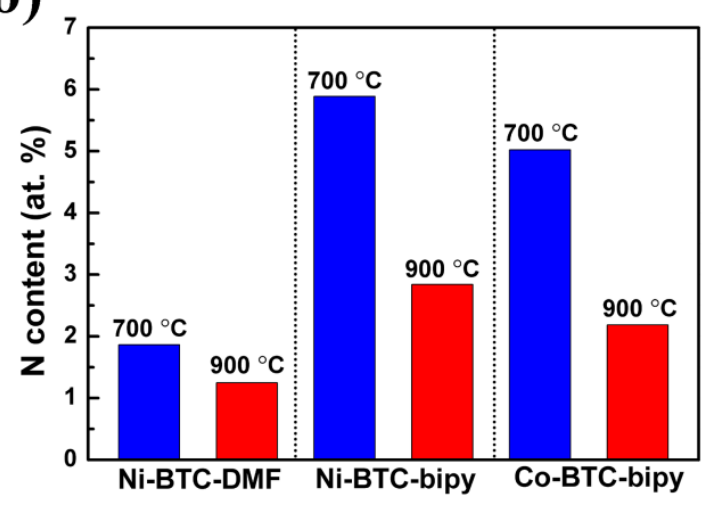

Figure 2. (a) The $I_{\mathrm{D}} / I_{\mathrm{G}}$ ratios of different catalysts based on Raman spectra (Figure S7-S9). (b) N content (at.\%) of different MOFs after pyrolysis under different temperatures, determined by $\mathrm{CHN}$ analysis based on total amount of $\mathrm{C}, \mathrm{H}$ and $\mathrm{N}$. 
(a)
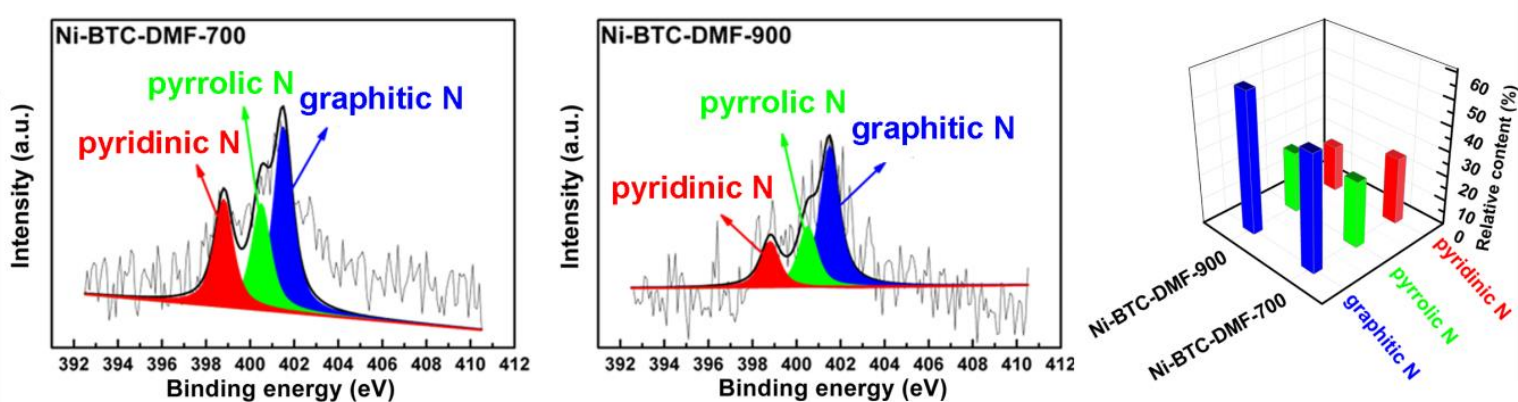

(b)
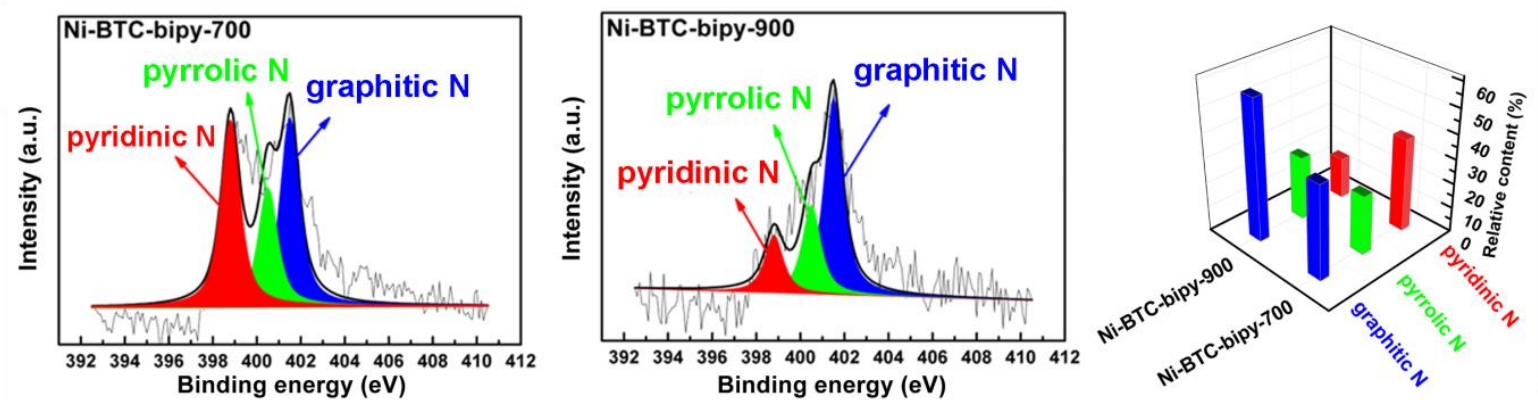

(c)
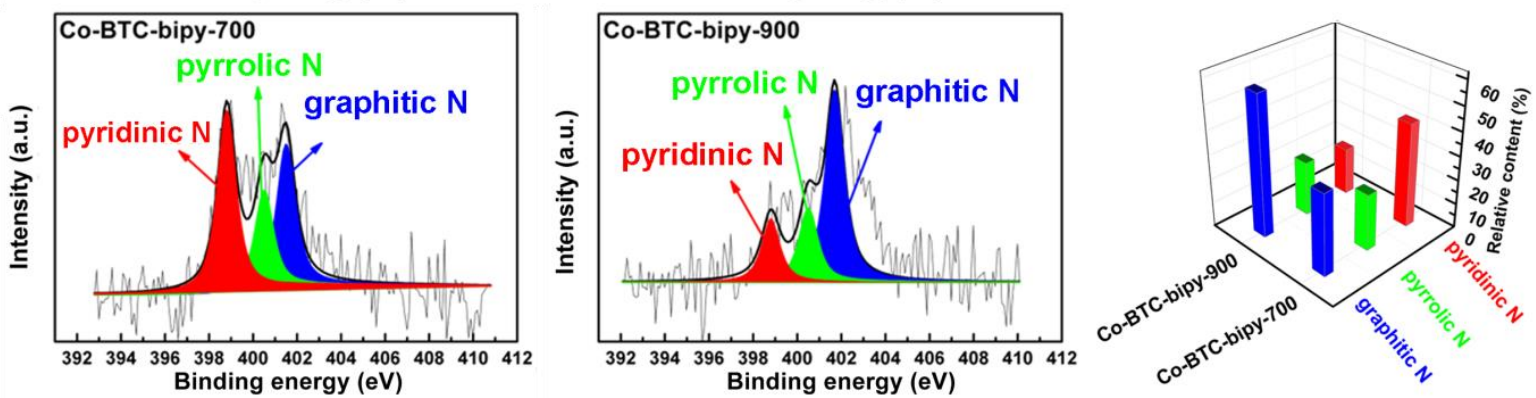

Figure 3. High-resolution XPS spectra of different N-heteroatom species and their relative content in $(a)$ Ni-BTC-DMF-700 and Ni-BTC-DMF-900 catalysts, (b) Ni-BTC-bipy-700 and Ni-BTC-bipy-900 catalysts, and $(c)$ Co-BTC-bipy-700 and Co-BTC-bipy-900 catalysts. 

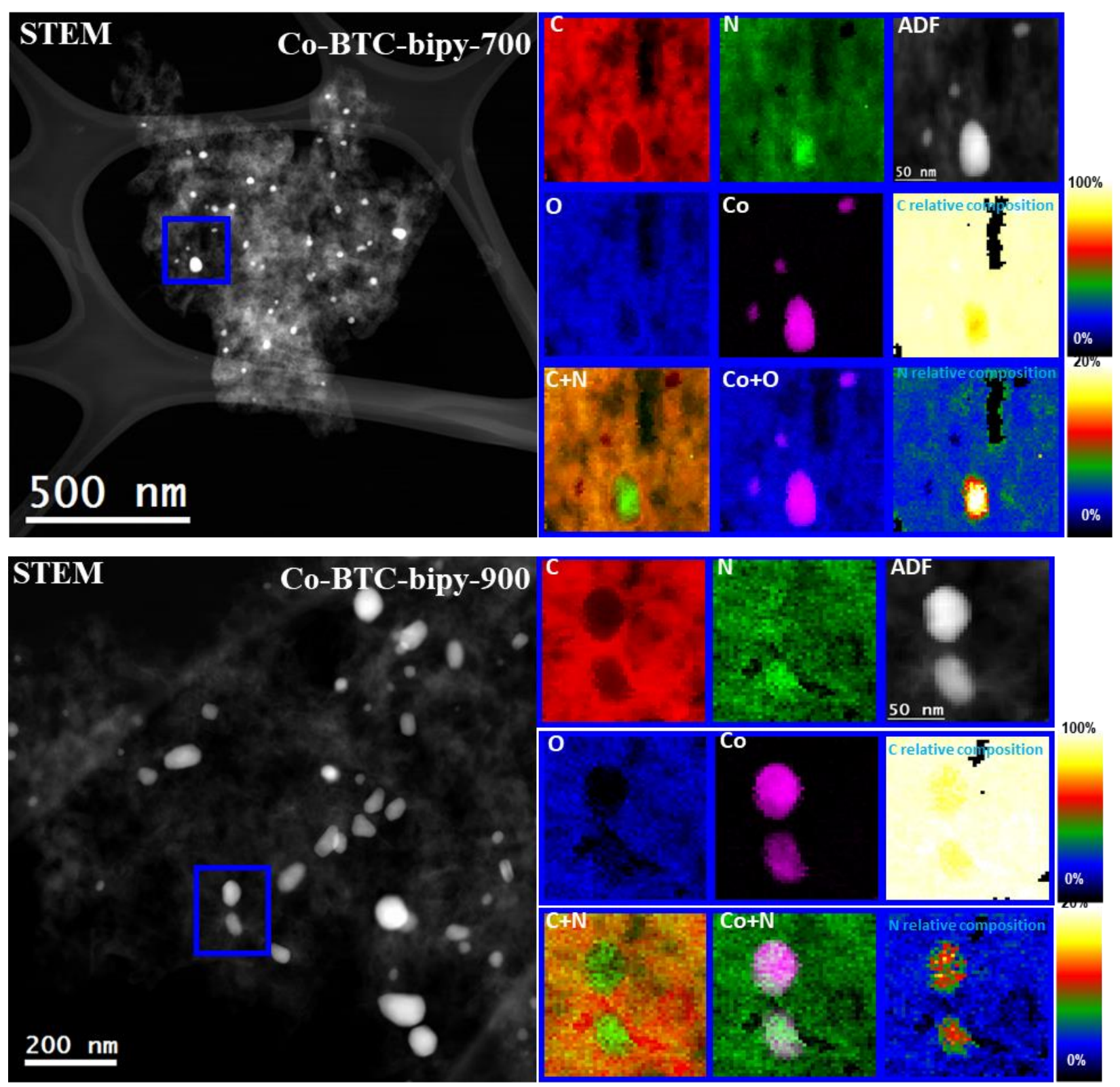

Figure 4. EELS chemical composition maps of Co-BTC-bipy-700 (top image) and Co-BTC-bipy-900 (bottom image) electrocatalysts obtained from the blue rectangular area of the ADF-STEM micrograph. Individual C K-edge (red), N K-edge (green), O K-edge (blue), Co L 2,3 -edge (pink) composite maps and the relative composition maps of $\mathrm{C}$ (at $94.0 \pm 2.9 \%$ ) and $\mathrm{N}($ at $6.1 \pm 2.9 \%$ ) for Co-BTC-bipy-700 and the relative composition maps of C (at $94.9 \pm 11.6 \%)$ and $\mathrm{N}($ a: $3.7 \pm 2.3 \%)$ for Co-BTC-bipy-900. 


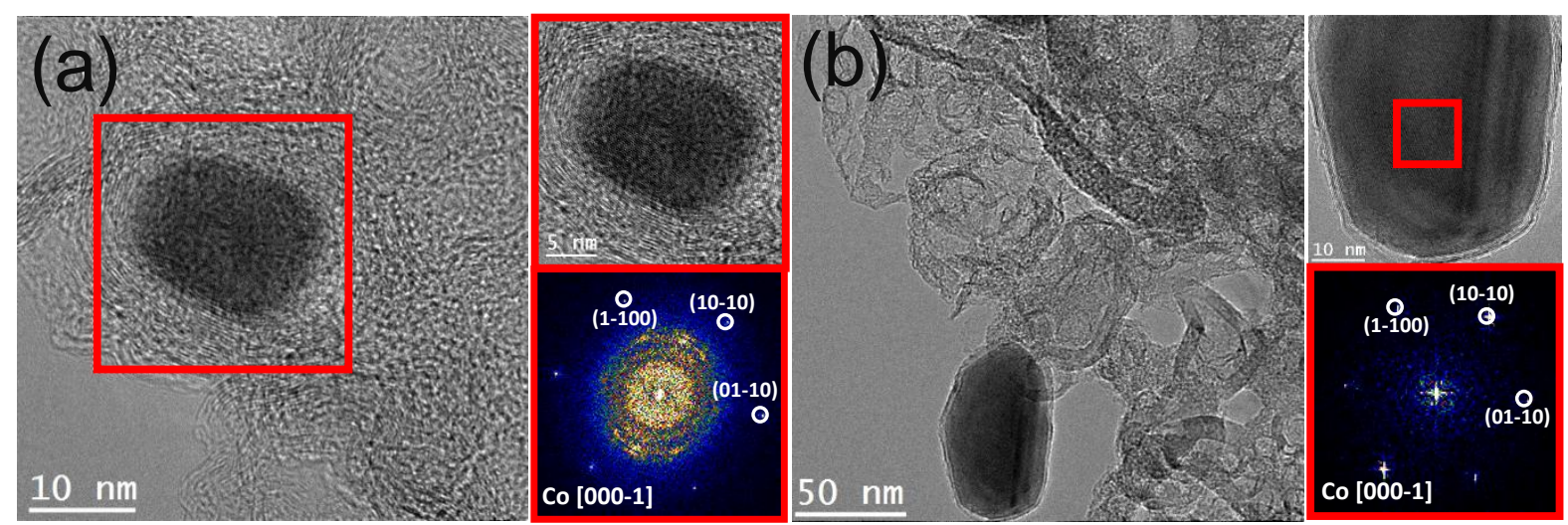

Figure 5. TEM images and corresponding power spectra (FFT) of (a) Co-BTC-bipy-700 and (b) Co-BTC-bipy-900 electrocatalysts. 


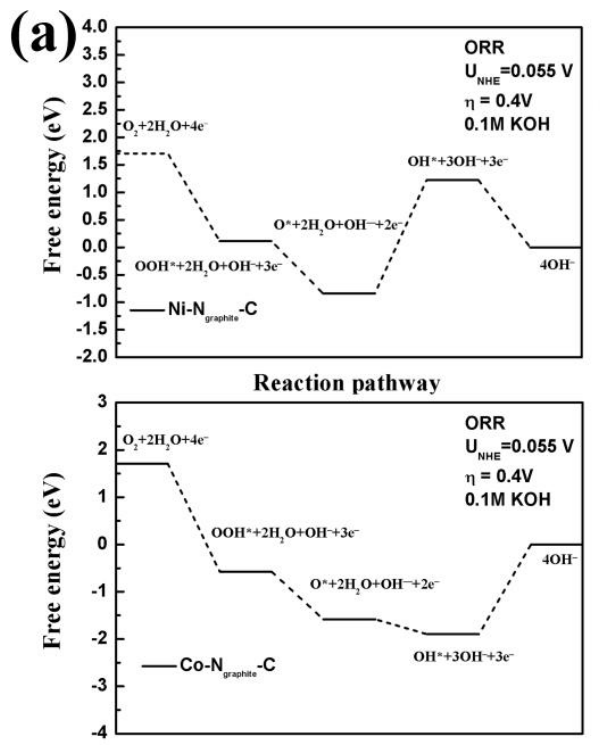

Reaction pathway
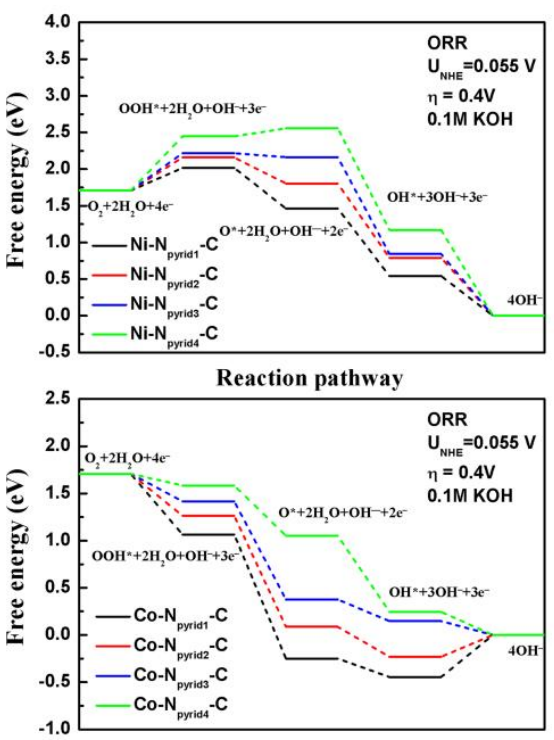

Reaction pathway
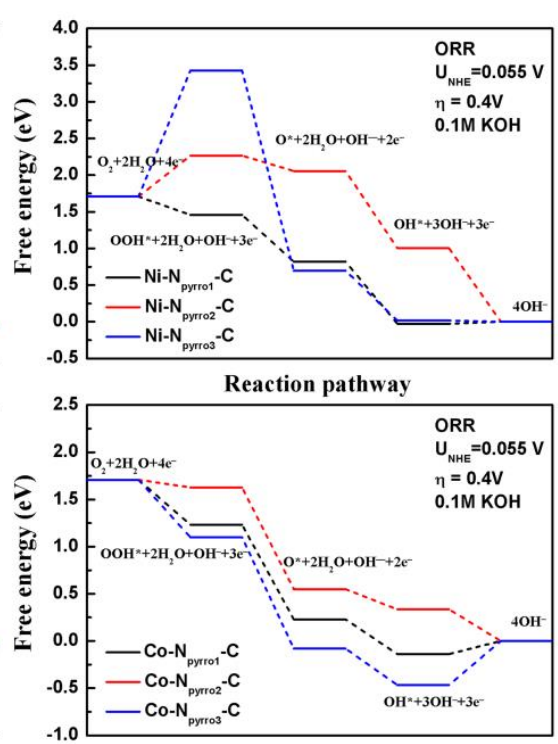

Reaction pathway

(b)

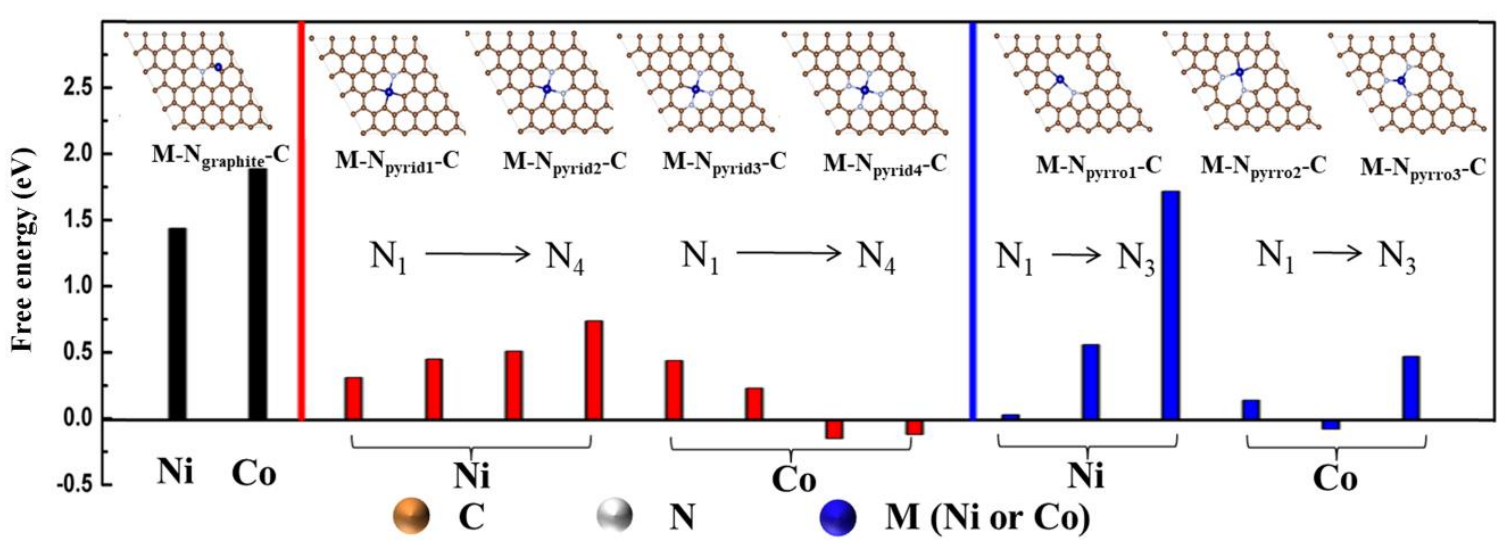

Figure 6. (a) Free energy variations of ORR elementary steps and (b) rate-determining steps for different M-N-C structures. Inset in (b) shows top views of the potential configurations of M-N-C structure surfaces. Gold, white and blue balls represent $\mathrm{C}, \mathrm{N}$ and $\mathrm{M}(\mathrm{M}=\mathrm{Ni}$ or $\mathrm{Co})$ atoms, respectively. 


\section{Temperature effects}

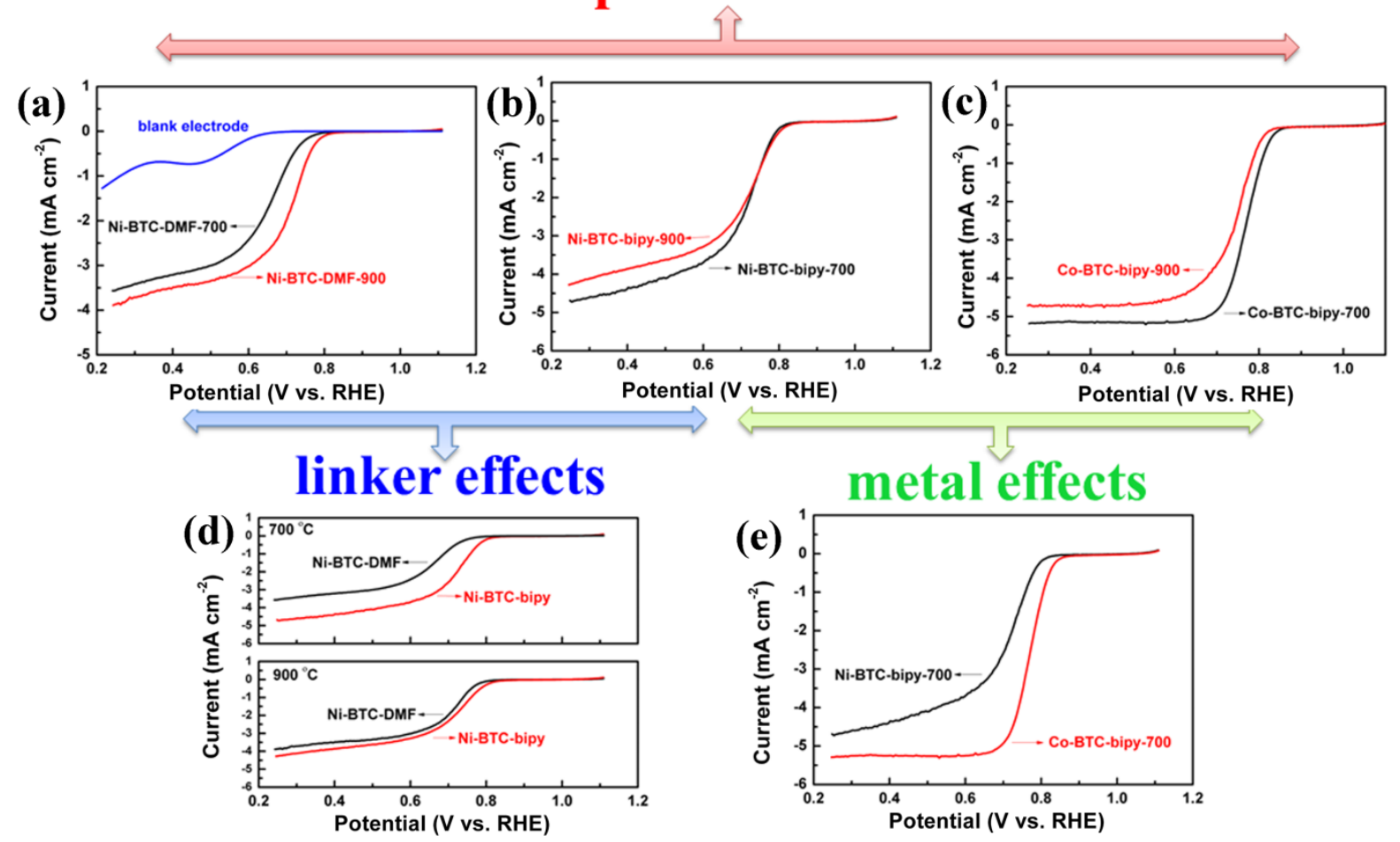

Figure 7. Linear scan voltammograms of different catalysts at a rotating speed of $1600 \mathrm{rpm}$ in $\mathrm{O}_{2}$-saturated $0.1 \mathrm{M}$ $\mathrm{KOH}$ at a scan rate of $10 \mathrm{mV} \mathrm{s}{ }^{-1}$ : (a) Ni-BTC-DMF-700 and Ni-BTC-DMF-900 electrocatalysts; (b) Ni-BTC-bipy-700 and Ni-BTC-bipy-900 electrocatalysts; (c) Co-BTC-bipy-700 and Co-BTC-bipy-900 electrocatalysts; (d) Ni-BTC-DMF-700, Ni-BTC-DMF-900, Ni-BTC-bipy-700 and Ni-BTC-bipy-900 electrocatalysts; (e) Ni-BTC-bipy-700 and Co-BTC-bipy-700 electrocatalysts. 

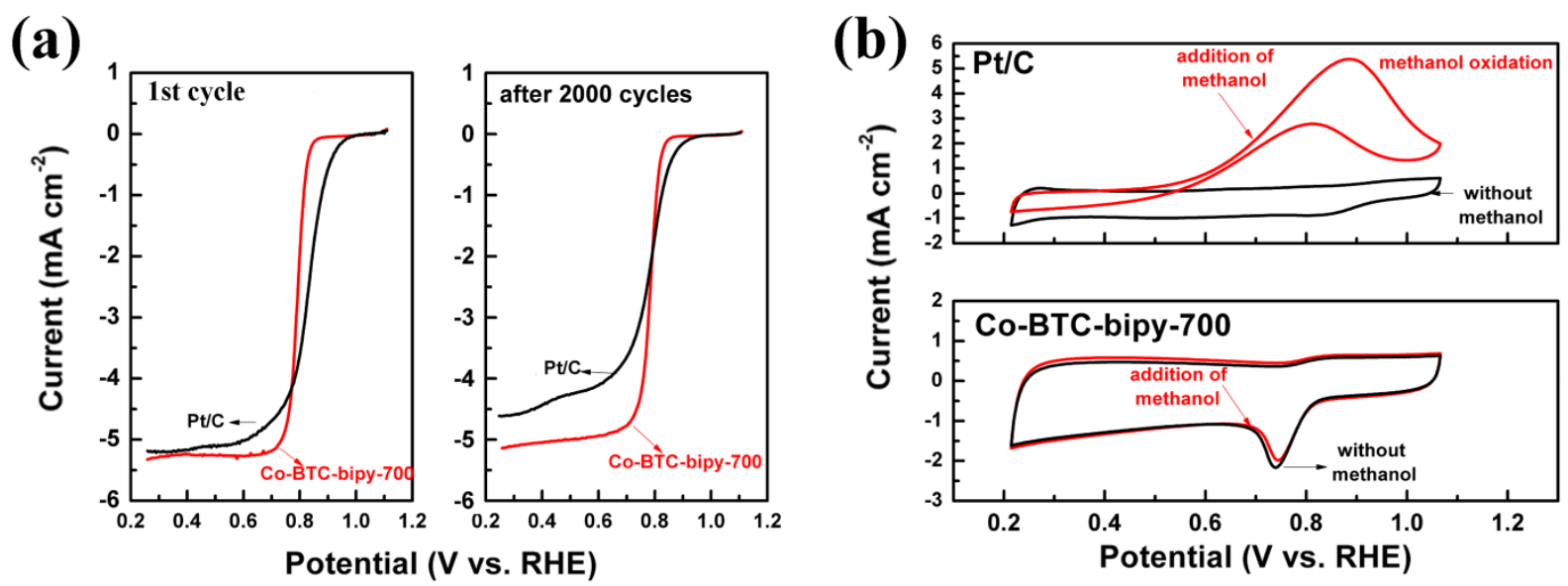

Figure 8. (a) Linear scan voltammograms (LSV) of Pt/C and Co-BTC-bipy-700 electrocatalysts on a RDE at a rotation speed of $1600 \mathrm{rpm}$ in $\mathrm{O}_{2}$-saturated $0.1 \mathrm{M} \mathrm{KOH}$ at a scan rate of $10 \mathrm{mV} \mathrm{s}^{-1}$ before and after cycling tests (in the range of $0.5 \mathrm{~V}-1 \mathrm{~V}$ vs. RHE). (b) Cyclic voltammograms (CV) of Pt/C and Co-BTC-bipy-700 electrocatalysts at a scan rate of $50 \mathrm{mV} \mathrm{s}^{-1}$ without the addition of methanol and after the addition of $1 \mathrm{M}$ methanol. 
(a)

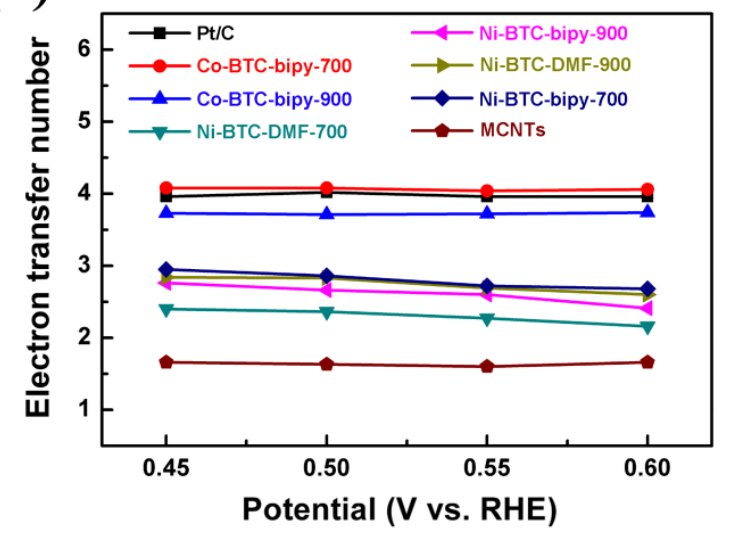

(b)

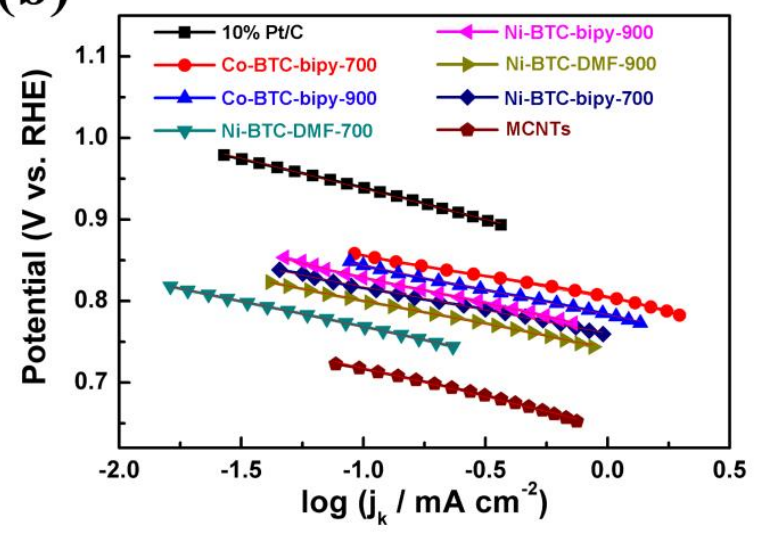

Figure 9. (a) Corresponding electron transfer number during ORR tests at various potentials based on Koutecky-Levich plots of different electrocatalysts (Figure S24b-S31b). (b) Tafel plots derived from the polarization curves (Figure S24a-S31a) at a rotating speed of $1600 \mathrm{rpm}$ in $\mathrm{O}_{2}$-saturated $0.1 \mathrm{M} \mathrm{KOH}$ at scan rate of $10 \mathrm{mV} \mathrm{s}^{-1}$. 
(a)

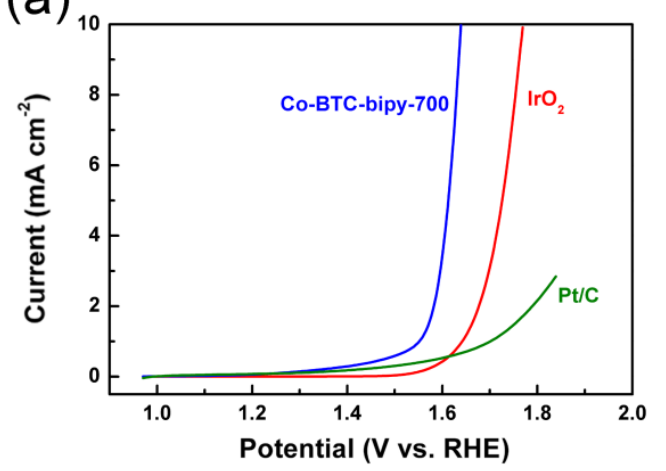

(c)

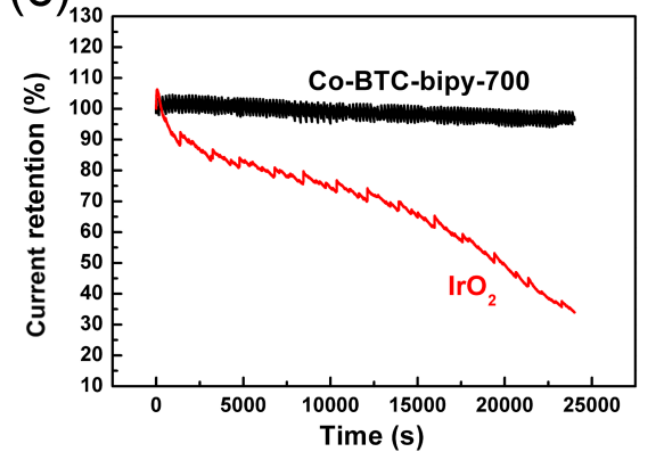

(b)

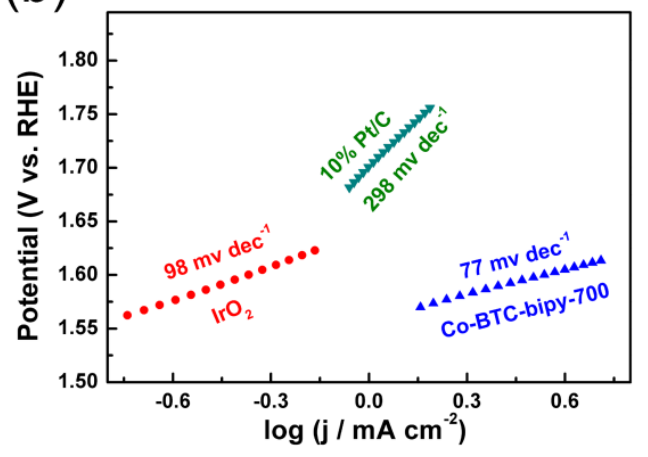

(d)

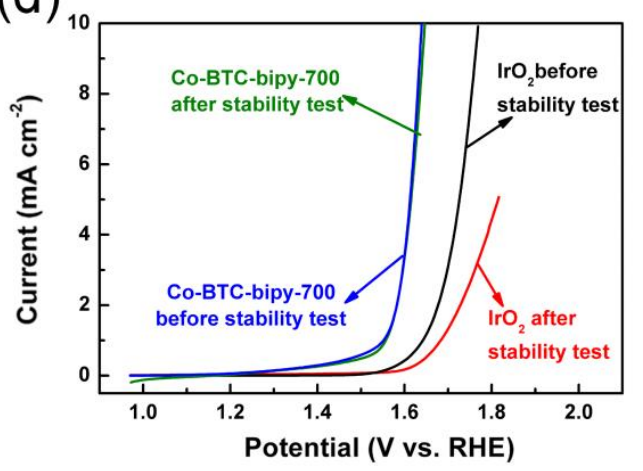

Figure 10. (a) OER polarization curves of $\mathrm{Pt} / \mathrm{C}, \mathrm{IrO}_{2}$ and Co-BTC-bipy-700 catalysts on a $\mathrm{RDE}$ rotating at 1600 rpm in $0.1 \mathrm{M} \mathrm{KOH}$; $(b)$ Corresponding Tafel plots obtained from the polarization curves; $(c)$ OER stability test of $\mathrm{IrO}_{2}$ and Co-BTC-bipy-700 catalysts with a constant applied potential of $1.7 \mathrm{~V} v$ s. RHE in $0.1 \mathrm{M} \mathrm{KOH}$; (d) OER polarization curves of $\mathrm{IrO}_{2}$ and Co-BTC-bipy-700 catalysts at a rotation speed of $1600 \mathrm{rpm}$ in $0.1 \mathrm{M} \mathrm{KOH}$ before and after stability tests. 
(a)
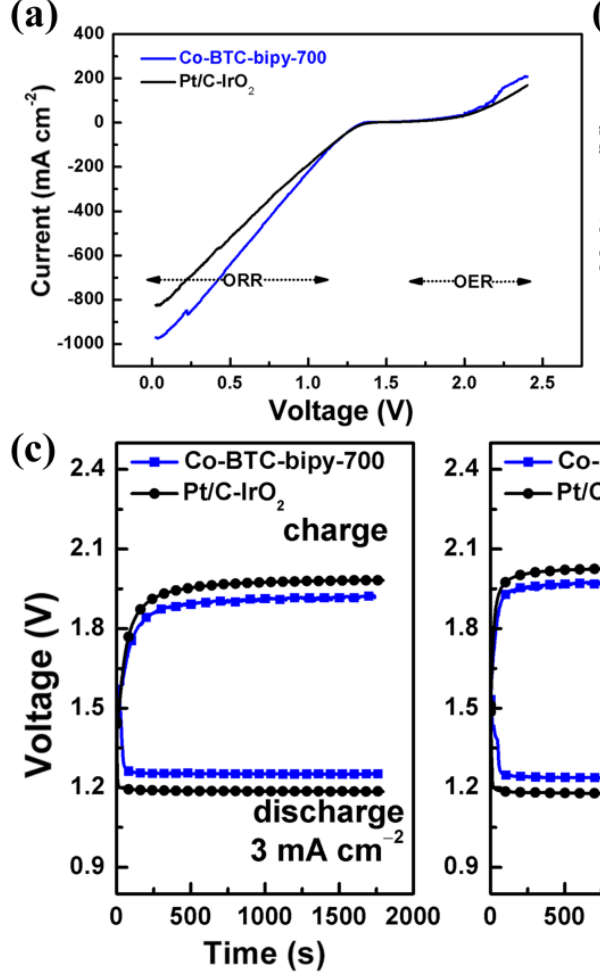

(b)

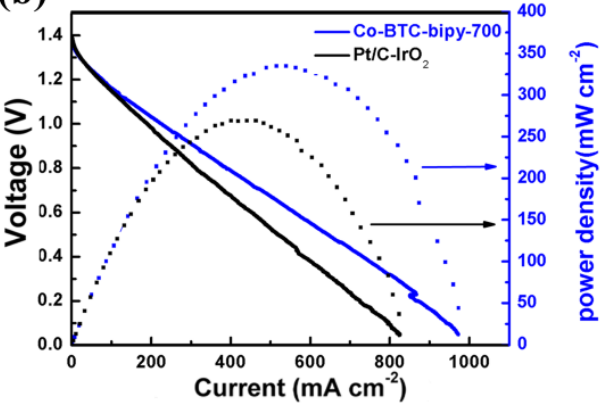

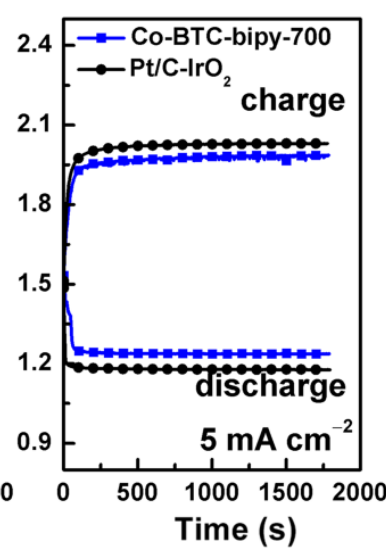

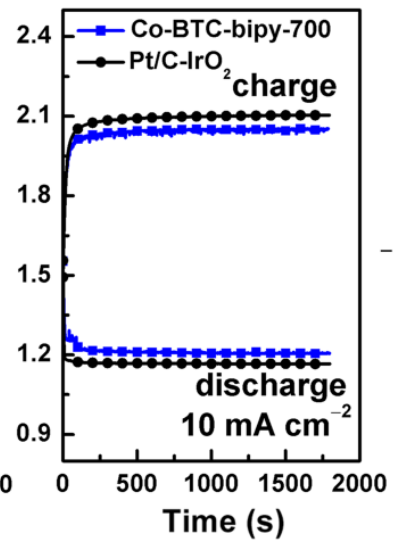

Figure 11 The $i-V$ polarization $(a)$ and power density $(b)$ curves of $\mathrm{Zn}$-air batteries based on $\mathrm{Pt} / \mathrm{C}-\mathrm{IrO} \mathrm{O}_{2}$ and

Co-BTC-bipy-700 catalysts. (c) Charge-discharge curves of $\mathrm{Zn}$-air batteries based on $\mathrm{Pt} / \mathrm{C}-\mathrm{IrO}{ }_{2}$ and Co-BTC-bipy-700 catalysts at different current densities after 30 cycles. 